\title{
The Two Faces of the Guanyl Radical: Molecular Context and Behavior
}

\author{
Chryssostomos Chatgilialoglu ${ }^{1,2}$ (D)
}

1 ISOF, Consiglio Nazionale delle Ricerche, 40129 Bologna, Italy; chrys@isof.cnr.it; Tel.: +39-051-6398309

2 Center of Advanced Technologies, Adam Mickiewicz University, 61-712 Poznań, Poland

\section{check for} updates

Citation: Chatgilialoglu, C. The Two Faces of the Guanyl Radical: Molecular Context and Behavior. Molecules 2021, 26, 3511. https:// doi.org/10.3390/molecules26123511

Academic Editor: Nicola Borbone

Received: 6 April 2021

Accepted: 1 June 2021

Published: 9 June 2021

Publisher's Note: MDPI stays neutral with regard to jurisdictional claims in published maps and institutional affiliations.

Copyright: (C) 2021 by the author. Licensee MDPI, Basel, Switzerland. This article is an open access article distributed under the terms and conditions of the Creative Commons Attribution (CC BY) license (https:/ / creativecommons.org/licenses/by/ $4.0 /)$.

\begin{abstract}
The guanyl radical or neutral guanine radical $\mathrm{G}(-\mathrm{H})^{\bullet}$ results from the loss of a hydrogen atom $\left(\mathrm{H}^{\bullet}\right)$ or an electron/proton $\left(\mathrm{e}^{-} / \mathrm{H}^{+}\right)$couple from the guanine structures $(\mathrm{G})$. The guanyl radical exists in two tautomeric forms. As the modes of formation of the two tautomers, their relationship and reactivity at the nucleoside level are subjects of intense research and are discussed in a holistic manner, including time-resolved spectroscopies, product studies, and relevant theoretical calculations. Particular attention is given to the one-electron oxidation of the GC pair and the complex mechanism of the deprotonation vs. hydration step of $\mathrm{GC}^{\bullet+}$ pair. The role of the two G(-H) ${ }^{\bullet}$ tautomers in singleand double-stranded oligonucleotides and the G-quadruplex, the supramolecular arrangement that attracts interest for its biological consequences, are considered. The importance of biomarkers of guanine DNA damage is also addressed.
\end{abstract}

Keywords: guanine; guanyl radical; tautomerism; guanine radical cation; oligonucleotides; DNA; G-quadruplex; time-resolved spectroscopies; reactive oxygen species (ROS); oxidation

\section{The Guanine Sink}

The free radical chemistry associated with guanine (Gua) and its derivatives, guanosine (Guo), 2'-deoxyguanosine (dGuo), guanosine-5'-monophosphate (GMP), and 2'deoxyguanosine-5'-monophosphate (dGMP), is of particular interest due to its biological relevance. Indeed, this reactivity is by far the most involved in oxidative DNA damage, initiated by reactive oxygen species (ROS) generated by normal cellular metabolism, or by exogenous sources such as ionizing or ultraviolet irradiation [1-3]. In the thirty years since the discovery of long-range charge transport in DNA, as reviewed by Barton and coworkers [4-6], a large body of experimental data have accumulated showing that the one-electron oxidation of DNA produces a hole that can migrate through the double helix with the final destination at the G sites [4-10]. Among the four common DNA bases (A, $G, T$, and $C), G$ is the most readily oxidized to the $G$ radical cation $\left(G^{\bullet+}\right)$, which is also the putative initial intermediate in the oxidative DNA damage. Thus, there have been numerous studies on the formation and behavior of $\mathrm{G}^{\bullet+}$ as a nucleoside and in oligonucleotides (ODNs) using spectroscopic and product studies. Upon formation of $\mathrm{G}^{\bullet+}$, fast deprotonation occurs by the loss of a proton to give the guanyl radical $\mathrm{G}(-\mathrm{H})^{\bullet}$, also named the guanine radical or neutral guanine radical. The main objective of this review is to summarize the behavior of $\mathrm{G}(-\mathrm{H})^{\bullet}$ in nucleosides and nucleotides and give an overview of its formation in a macromolecular environment, such as single-stranded (ss), double-stranded (ds) ODNs, and G-quadruplex arrangements.

\section{The Two Tautomers of the Guanyl Radical}

The guanyl radical $\mathrm{G}(-\mathrm{H})^{\bullet}$ corresponds to any intermediate that has lost an $\mathrm{H}$-atom or an electron/proton $\left(\mathrm{e}^{-} / \mathrm{H}^{+}\right)$couple from the $\mathrm{G}$ moiety. $\mathrm{G}(-\mathrm{H})^{\bullet}$ is one of the most recurrent and intensively studied transient species. The reason is obvious, as dGuo (1, $\mathrm{R}=2^{\prime}$-deoxyribose) is one of the building blocks of DNA with the lowest oxidation potential (Figure 1). The chemistry of $\mathrm{G}(-\mathrm{H})^{\bullet}$ depends on the molecular context where it 
belongs (free base, nucleoside in ribo or deoxyribo forms, ss- or ds-ODNs including multi-G sequences, RNA, DNA, and G-quadruplex). Although numerous mechanistic studies have been performed during recent years, the emerging picture is still incomplete, with several unanswered questions and divergent opinions. The extrapolation of its chemistry from simple nucleosides to more complex environments (e.g., DNA) can be misleading. This situation often generates confusion to the newcomers in the field. In the present article, the existing dichotomies among mechanistic insights are examined and critically discussed to give a reasoned overview of the guanyl radical structure and behavior.<smiles>[R]c1nc(N)[nH]c(=O)c1[O-]</smiles>

$1, \mathrm{G}$<smiles></smiles>

2, $\mathrm{G}(\mathrm{N} 1-\mathrm{H})^{\cdot}$

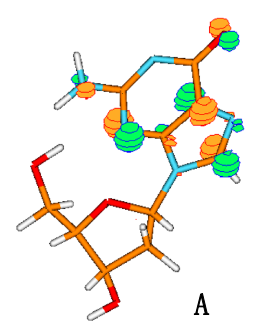<smiles></smiles>

$3, \mathrm{G}(\mathrm{N} 2-\mathrm{H})^{\circ}$

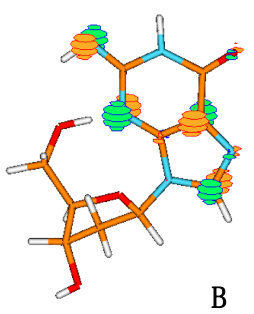

Figure 1. Structure 1 represents the guanine moiety in guanosine (Guo), $2^{\prime}$-deoxyguanosine (dGuo), guanosine-5'- monophosphate (GMP), 2'-deoxyguanosine-5'-monophosphate (dGMP), or 3' $5^{\prime} 5^{\prime}$-cyclic guanosine monophosphate (cGMP); the atom numbering of the guanine moiety is given in red. The corresponding guanyl radicals $\mathrm{G}(\mathrm{N} 1-\mathrm{H})^{\bullet}(2)$ or $\mathrm{G}(\mathrm{N} 2-\mathrm{H})^{\bullet}(3)$; the part of the molecule involved in tautomerization is highlighted in red. SOMO of the two forms of guanyl radical G(N1-H) ${ }^{\bullet}(\mathbf{A})$ and $\mathrm{G}(\mathrm{N} 2-\mathrm{H})^{\bullet}(\mathrm{B})$ computed at the B3LYP/6-311G ${ }^{* *}$ level (taken from ref [11]).

Figure 1 shows two tautomeric structures of $\mathrm{G}(-\mathrm{H})^{\bullet}$ : form $\mathbf{2}$ or $\mathrm{G}(\mathrm{N} 1-\mathrm{H})^{\bullet}$ that has lost $\mathrm{H}$ from the $\mathrm{N} 1$ position, and form 3 or $\mathrm{G}(\mathrm{N} 2-\mathrm{H})^{\bullet}$ that has lost $\mathrm{H}$ from the $\mathrm{N} 2$ position. The acronyms $\mathrm{G}(\mathrm{N} 1-\mathrm{H})^{\bullet}$ and $\mathrm{G}(\mathrm{N} 2-\mathrm{H})^{\bullet}$ have been commonly used in the recent literature and are used throughout this review; alternative acronyms have been used: $\mathrm{G}^{\bullet}, \mathrm{N}^{\circ} \mathrm{G}^{\bullet}$, $\left(\mathrm{G}-\mathrm{H}_{1}\right)^{\bullet}$ or the aminic form for $\mathrm{G}(\mathrm{N} 1-\mathrm{H})^{\bullet}$, and $\mathrm{N}(2) \mathrm{G}^{\bullet}, \mathrm{N} 2 \mathrm{G}^{\bullet},\left(\mathrm{G}-\mathrm{H}_{2}\right)^{\bullet}, \mathrm{G}\left(\mathrm{N}^{2}-\mathrm{H}\right)^{\bullet}$ or the iminic form for $\mathrm{G}(\mathrm{N} 2-\mathrm{H})^{\bullet}$. Figure 1 also shows the distribution of the unpaired electron in the SOMO of $\mathrm{G}(\mathrm{N} 1-\mathrm{H})^{\bullet}(\mathbf{A})$ and $\mathrm{G}(\mathrm{N} 2-\mathrm{H})^{\bullet}(\mathbf{B})$ computed at the B3LYP/6-311G ${ }^{* *}$ level [11]. In $\mathbf{A}$, the unpaired electron is mainly localized at the $\mathrm{N} 3, \mathrm{O} 6, \mathrm{C} 5$, and C8 atoms (spin densities of $0.30,0.34,0.21$, and 0.27 , respectively), whereas, in $\mathbf{B}$, the unpaired electron is mainly localized at the N3, C5, C8, and N2 atoms (spin densities of $0.34,0.29,0.22$, and 0.39 , respectively) [11]. As each tautomer has various resonance forms (discussed in some detail in reference [11]), the reported drawings for radicals 2 and 3 , where the unpaired electron is placed in the $\mathrm{C} 5$ position, are chosen for a facile distinction of the two tautomers (Figure 1).

\section{One-Electron Oxidation of Guanine Derivatives}

In the guanine derivatives $1(G)$, the two $p K_{a}$ values of 2.5 and 9.3 are related to the protonation and deprotonation steps, respectively $[12,13]$. Early work by pulse radiolysis studies with both conductometric and optical detection showed that the one-electron oxidations of Guo and dGuo by the powerful $\mathrm{SO}_{4}{ }^{--}$or the milder $\mathrm{Br}_{2}{ }^{\bullet-}$ oxidants (see Appendix A) afford the corresponding radical cation $\mathrm{G}^{\bullet+}$, which is in agreement with the reduction potentials of the reactants $\mathrm{E}_{7}(\mathbf{2} / \mathbf{1})=1.29 \mathrm{~V}, \mathrm{E}^{\circ}\left(\mathrm{SO}_{4}{ }^{--} / \mathrm{SO}_{4}{ }^{2-}\right) \approx 2.43 \mathrm{~V}$, and $E^{\circ}\left(\mathrm{Br}_{2}{ }^{--} / 2 \mathrm{Br}^{-}\right)=1.66 \mathrm{~V}[12,14,15]$. The determined $\mathrm{p} K_{\mathrm{a}}$ value of 3.9 in $\mathrm{G}^{\bullet+}$ is asso- 
ciated with the loss of a proton from $\mathrm{N} 1$ to give the guanyl radical G(N1-H) ${ }^{\bullet}$ (Figure 2); at high $\mathrm{pH}, \mathrm{G}(\mathrm{N} 1-\mathrm{H})^{\bullet}$ further deprotonates to produce $\mathrm{G}(-2 \mathrm{H})^{\bullet-}$ with $\mathrm{p} K_{\mathrm{a}} 10.7[12,13]$. Therefore, the one-electron oxidation of $\mathbf{1}$ in the $\mathrm{pH}$ range 5-8 affords the guanyl radical $\mathrm{G}(\mathrm{N} 1-\mathrm{H})^{\bullet}$. The deprotonation rate constant was measured at $\mathrm{pH} 7$ by pulse radiolysis to be $1.8 \times 10^{7} \mathrm{~s}^{-1}$ at r.t., showing a $k\left(\mathrm{H}_{2} \mathrm{O}\right) / k\left(\mathrm{D}_{2} \mathrm{O}\right)$ of 1.7 [16] and by laser flash photolysis to be $1.5 \times 10^{7} \mathrm{~s}^{-1}$ with the activation energy of $15.1 \pm 1.5 \mathrm{~kJ} \mathrm{~mol}^{-1}$ [17]. DFT calculations on solvation models were used to calculate the deprotonation potential energy profile [17]. The one-electron oxidation of Guo by $\mathrm{Br}_{2}{ }^{\bullet-}$ was investigated by pulse radiolysis coupled with transient electrochemistry; the intermediate $\mathrm{G}(\mathrm{N} 1-\mathrm{H})^{\bullet}$ (at $28 \pm 4 \mu \mathrm{M}$ concentration) decays by a second-order rate of $3.4 \times 10^{7} \mathrm{M}^{-1} \mathrm{~s}^{-1}$, and there is competition between the oxidation and reduction of $\mathrm{G}(\mathrm{N} 1-\mathrm{H})^{\bullet}$, i.e., the ability of the radical to be either oxidized or reduced, presumably via disproportionation rather than the dimerization process [18].

(A)

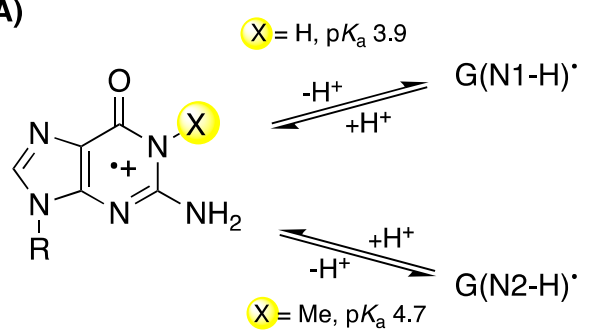

(B)<smiles></smiles>

Figure 2. (A) The deprotonation of $\mathrm{G}^{\bullet+}(\mathrm{X}=\mathrm{H})$ and 1-Me- $\mathrm{G}^{\bullet+}(\mathrm{X}=\mathrm{Me})$ affording $\mathrm{G}(\mathrm{N} 1-\mathrm{H})^{\bullet}$ and $\mathrm{G}(\mathrm{N} 2-\mathrm{H})^{\bullet}$, respectively. (B) Conformational isomers of $\mathrm{G}(\mathrm{N} 2-\mathrm{H})^{\bullet}$ in syn and anti with respect to $\mathrm{N} 3$ atom; the earlier syn- and anti-conformations were defined with respect to $\mathrm{N} 1-\mathrm{H}$ [11] and, as syn and anti with respect to N3 have been commonly used in the recent literature, these notations are adopted in the text.

On the other hand, when the N1-H moiety is replaced by N1-Me, the deprotonation occurs from the exocyclic $\mathrm{NH}_{2}$ group and associates with a $\mathrm{p} K_{\mathrm{a}}$ value of 4.7 (Figure 2A) [14] Indeed, theoretical calculations have suggested that deprotonation from the N2-H moiety is competitive with deprotonation from N1-H. Both EPR and UV-visible spectra of the one-electron-oxidized $\mathrm{dGuo}$ by $\mathrm{Cl}_{2}{ }^{\bullet-}$ are reported for each of the species: $\mathrm{G}^{\bullet+}, \mathrm{G}(-\mathrm{H})^{\bullet}$, and $\mathrm{G}(-2 \mathrm{H})^{\bullet-}$ in aqueous medium at $77 \mathrm{~K}$ [19]. The experimental data corroborated by DFT calculations indicated that $\mathrm{G}(\mathrm{N} 1-\mathrm{H})^{\bullet}$ is favored over $\mathrm{G}(\mathrm{N} 2-\mathrm{H})^{\bullet}$ in environments with high dielectric constants, such as water. Furthermore, the two conformational isomers of $\mathrm{G}(\mathrm{N} 2-\mathrm{H})^{\bullet}$ in which the remaining $\mathrm{N} 2-\mathrm{H}$ is either syn or anti with respect to the guanine $\mathrm{N} 3$ atom were calculated, finding that the syn-conformer is lower in energy that the anticonformer is (Figure 2B) [19]; see also the three-dimensional structure B in Figure 1 that refers to the syn-conformer [11].

The oxidation of GMP and dGMP has also been reported in some detail. It has been reported that the presence of the phosphate group in $\mathrm{dGMP}^{\bullet+}$ does not significantly affect the prototropic equilibria of the guanine moiety. ENDOR studies carried out using X-ray-irradiated single crystals of dGMP showed that the deprotonation of $\mathrm{G}^{\bullet+}$ occurs from $\mathrm{N} 2$ rather than the $\mathrm{N} 1$ position with the formation of $\mathrm{G}(\mathrm{N} 2-\mathrm{H})^{\bullet}$ [20]. More recently, the structure and reactivity of $\mathrm{G}^{\bullet+}$ and $\mathrm{G}(-\mathrm{H})^{\bullet}$ have been investigated in aqueous solutions by using pulse radiolysis (Raman and UV-visible detection) from the $5^{\prime}$-dGMP oxidation by $\mathrm{SO}_{4}{ }^{\bullet-}$ at $\mathrm{pH} 7.4$ [21], or by the photo-oxidation of $5^{\prime}$-GMP by the $3,3^{\prime}, 4,4^{\prime}-$ benzophenone tetracarboxylic acid (TCBP) triplet within the $\mathrm{pH}$ range of $2-12$ using laser flash photolysis and time-resolved chemically induced dynamic nuclear polarization (CIDNP) [22-24]. There is strong spectroscopic evidence that $\mathrm{G}(\mathrm{N} 1-\mathrm{H})^{\bullet}$ is further transformed to a new species in the range of $\mathrm{pH} 7.4-8.0[21,23,24]$. The formation of this species shows a $\mathrm{pH}$ dependence, suggesting that it is the $\mathrm{G}$ radical cation, named $\left(\mathrm{G}^{\bullet+}\right)^{\prime}$, and is tentatively assigned to the protonation at the N7 position of $\mathrm{G}(\mathrm{N} 1-\mathrm{H})^{\bullet}$ with a rate constant of $8.1 \times 10^{6} \mathrm{~s}^{-1}$. Although this suggestion is strongly criticized based on theoretical 
calculations [25], further support is provided by time-resolved CIDNP [23,24]. From the full analysis of the $\mathrm{pH}$-dependent CIDNP kinetics, the protonation and deprotonation behavior was quantitatively characterized, giving $\mathrm{p} K_{\mathrm{a}}=8.0 \pm 0.2$ of the radical $\left(\mathrm{G}^{\bullet+}\right)^{\prime}[24]$. The same spectroscopical method suggested the formation of the radical dication $\mathrm{G}^{\bullet++}$ with $\mathrm{p} K_{\mathrm{a}}=2.1$ [22]. The above-described experiments are based on the oxidation of GMP or dGMP and the corresponding guanyl radical. It is well-known that GMP and dGMP with respect to Guo and dGuo have two extra $\mathrm{p} K_{\mathrm{a}}$ values of 0.3 and 6.3 that correspond to the deprotonation of the phosphate moiety, viz. $\mathrm{P}(\mathrm{O})(\mathrm{OH})_{2}$ and $\mathrm{P}(\mathrm{O})(\mathrm{OH}) \mathrm{O}^{-}$[26]. Although the observed $\mathrm{p} K_{\mathrm{a}}$ values around 2 and 8 could be associated with the deprotonation of the phosphate moiety in the one-electron oxidation of GMP or dGMP, in the earlier report, the authors mentioned that the results are qualitatively the same by replacing GMP with Guo [23]. More detailed analysis on Guo is necessary to clarify this aspect.

\section{One-Electron Reduction of 8-Haloguanine Derivatives}

The first directly observed differences of the two tautomeric forms of $\mathrm{G}(-\mathrm{H})^{\bullet}$ came from a pulse radiolysis study. Using the reaction of hydrated electrons $\left(\mathrm{e}_{\mathrm{aq}}{ }^{-}\right)$with 8-haloguanosine (halo $=\mathrm{Cl}, \mathrm{Br}$, and I), the two observed short-lived intermediates, which show a substantial difference in their absorption spectra around $620 \mathrm{~nm}$, were assigned to the two $\mathrm{G}(-\mathrm{H})^{\bullet}$ tautomers [11]. The identification of various transient species and transition states has also been addressed computationally by means of time-dependent DFT (TD-B3LYP / 6$\left.311 \mathrm{G}^{* *} / / \mathrm{B} 1 \mathrm{~B} 95 / 6-31+\mathrm{G}^{* *}\right)$ calculations [11]. Figure 3 shows the transient UV-visible spectra of the reaction of 8-Br-Guo (4) with $\mathrm{e}_{\mathrm{aq}}{ }^{-}$to produce the less stable G(N2-H) ${ }^{\bullet}$ (in red color), followed by a tautomerization to give $\mathrm{G}(\mathrm{N} 1-\mathrm{H})^{\bullet}$ (in blue color), for which an identical spectrum was obtained by the one-electron oxidation of Guo (1). Theory suggests that the electron adduct of 8-Br-Guo protonated at C8 forms a loose $\pi$-complex with the $\mathrm{Br}$ atom situated above the molecular plane, and is prompt to eject $\mathrm{Br}^{-}$. Moreover, the transition state 5 for the elimination of anti-H from the $\mathrm{NH}_{2}$ group was found to be much more stable than the transition states for eliminations of syn- $\mathrm{H}$ by $18.0 \mathrm{~kJ} \mathrm{~mol}^{-1}$ and of N1$\mathrm{H}$ by $14.1 \mathrm{~kJ} \mathrm{~mol}^{-1}$. Presumably, the observed spectrum is the syn-G(N2-H)${ }^{\bullet}$ radical [11]. The band around $620 \mathrm{~nm}$ was also predicted very well by the DFT-TD calculations [27], i.e., $\lambda=616 \mathrm{~nm}, f=0.045$, and transition \{spin\}: $\mathrm{p}\left(\right.$ (out-of-phase $\left.\mathrm{N}^{\prime}{ }^{\prime}, \mathrm{N} 1, \mathrm{O}^{\prime}{ }^{\prime}\right) \rightarrow \mathrm{SOMO}$ (out-of-phase N2', N3, C5, C8) \{b\}.

The Arrhenius parameters for this tautomerization, the solvent kinetic isotope effect $\left(k\left(\mathrm{H}_{2} \mathrm{O}\right) / \mathrm{k}\left(\mathrm{D}_{2} \mathrm{O}\right)\right.$, and the calculations at the PCM/B1B95/6-31+G $\mathrm{G}^{* *} / / \mathrm{B} 1 \mathrm{~B} 95 / 6-31+\mathrm{G}^{* *}$ level suggested a complex transition state $\mathbf{6}$ for the water-assisted tautomerization [11,28,29]; the reaction mechanism of $\mathrm{e}_{\mathrm{aq}}{ }^{-}$with 4 reported in 2000 [29] was revised in 2005 [28], and the revision did not affect the experimental results (the kinetic data). For the ribose series, the rate constants for the transformation $\mathrm{G}(\mathrm{N} 2-\mathrm{H})^{\bullet} \rightarrow \mathrm{G}(\mathrm{N} 1-\mathrm{H})^{\bullet}$ were measured in $\mathrm{H}_{2} \mathrm{O}$ and $\mathrm{D}_{2} \mathrm{O}, k\left(\mathrm{H}_{2} \mathrm{O}\right)=5.0 \times 10^{4}$ $\mathrm{s}^{-1}$ and $k\left(\mathrm{D}_{2} \mathrm{O}\right)=6.2 \times 10^{3} \mathrm{~s}^{-1}$, respectively, with a solvent kinetic isotope effect of 8.0 [29]. The Arrhenius parameters, $\log \left(A / \mathrm{s}^{-1}\right)=8.7 \pm 0.4$ and $E_{\mathrm{a}}=23.0 \pm 2.5 \mathrm{~kJ} \mathrm{~mol}^{-1}$, were measured in the temperature range of $5.8-50.3^{\circ} \mathrm{C}$ [28]. The tautomerization is accelerated by phosphate and $\mathrm{H}^{+}$, with the rate constants $k_{\text {phosp }}=1.4 \times 10^{8} \mathrm{M}^{-1} \mathrm{~s}^{-1}$ at $\mathrm{pH} \sim 7$ and $\mathrm{k}_{\mathrm{H}+} \cong 1 \times 10^{10} \mathrm{M}^{-1} \mathrm{~s}^{-1}$ at $\mathrm{pH} 4$, respectively [29]. The $\mathrm{G}(\mathrm{N} 2-\mathrm{H})^{\bullet}$ is unreactive toward methyl viologen (MV2+) and molecular oxygen, whereas it is able to effect the oxidation of $N, N, N^{\prime}, N^{\prime}$-tetramethyl-pphenylenediamine (TMPD) with a rate constant of $k=1.7 \times 10^{9} \mathrm{M}^{-1} \mathrm{~s}^{-1}$ [29]. Figure 3 also shows the calculated transition state 6 for the water-assisted tautomerization computed at the PCM/B1B95/6-31+G**//B1B95/6-31+G** level. The computed value of $21.3 \mathrm{~kJ} \mathrm{~mol}^{-1}$ is in very good agreement with the experimental value of $23.0 \mathrm{~kJ} \mathrm{~mol}^{-1}$ [11]. Other authors [19] calculated an analogous reaction using the sugar moiety instead of 9-Me at the B3LYP / 6-31G(d) level and found an activation barrier of $78.2 \mathrm{~kJ} \mathrm{~mol}^{-1}$, confirming that the choice of theory and the location of the water molecule in the reagents have a profound effect on the outcome. Pulse radiolysis also revealed the "instantaneous" formation of $\mathrm{G}^{\bullet+}$ or $\mathrm{G}(-2 \mathrm{H})^{\bullet-}$ in the reaction of $\mathrm{e}_{\mathrm{aq}}{ }^{-}$with 8-Br-Guo in acid or basic solutions, and the 
observed $\mathrm{p} K_{\mathrm{a}}$ values of 3.8 and 10.4 matched well with the reported values of 3.9 and 10.7 for the oxidized Guo, respectively [29].

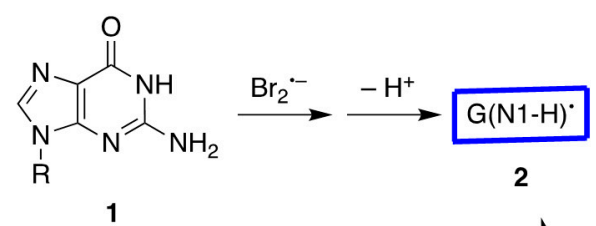

1

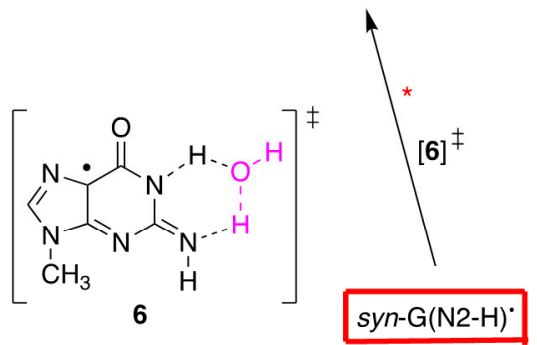

3

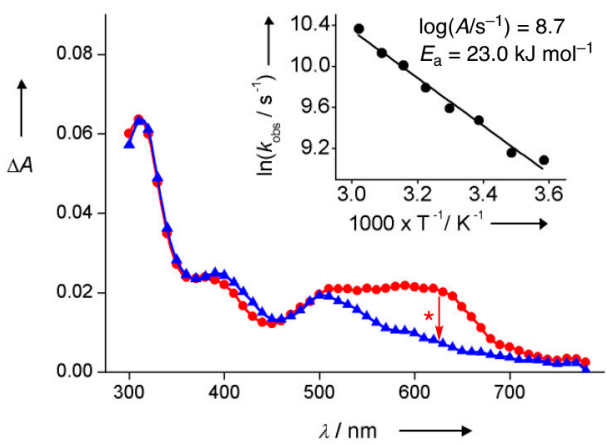

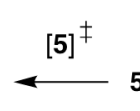

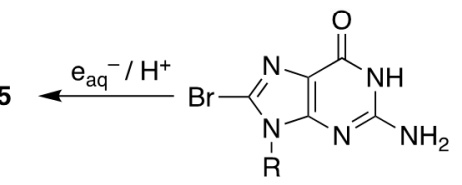

4

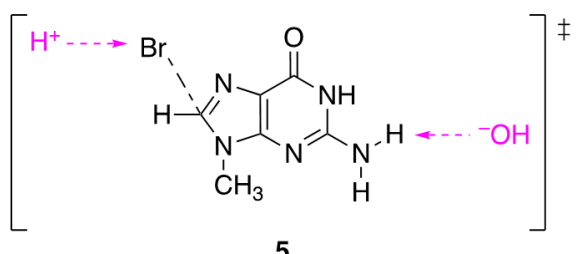

5

Figure 3. Oxidation of guanosine ${\mathbf{1 ~ b y ~} \mathrm{Br}_{2}}^{\bullet-}$ and the formation of transient guanyl radical 2 (in blue color). The reduction of 8 -bromoguanosine 4 by $\mathrm{e}_{\mathrm{aq}}{ }^{-}$and the transient guanyl radical 3 taken in $2 \mu$ s after the pulse (in red color); by monitoring the reaction at $620 \mathrm{~nm}$ (see red arrow), radical 3 is transformed to 2 with a first-order rate constant of $5 \times 10^{4} \mathrm{~s}^{-1}$ at room temperature with Arrhenius parameters reported in the insert (adapted from $[11,28]$ ). The transition state $\mathbf{5}$, for the deprotonation from $\mathrm{NH}_{2}$ by means of $\mathrm{HO}^{-}$during the elimination of $\mathrm{Br}^{-}$from the $\pi$-complex as $\mathrm{HBr}$, and the transition state 6 , for the $\mathrm{H}_{2} \mathrm{O}$-assisted tautomerization, were calculated at the PCM/B1B95/6$31+G^{* *} / /$ B1B95/6-31+G** level.

We discussed above the electron-coupled proton transfer (ECPT) reactions of 8-Br-Guo (4) at $\mathrm{pH} 7$. It is also worth mentioning the pulse radiolysis experiments under acidic conditions [29]. At $\mathrm{pH} 3$, the typical spectrum of $\mathrm{G}^{\bullet+}$ was generated in two steps: the first one was complete in less than $1 \mu \mathrm{s}$ and the second one in $\sim 8 \mu \mathrm{s}$, corresponding to the reactions of $\mathrm{eaq}^{-}$and $\mathrm{H}^{\bullet}$, respectively. In the $\gamma$-radiolysis study of 8-Br-Guo in aqueous solutions followed by product studies, the formation of Guo as a single product at various $\mathrm{pH}$ was shown. In $\mathrm{D}_{2} \mathrm{O}$ solutions, the quantitative incorporation of deuterium at the 8-position was also observed [29].

A variety of substituted 8-bromoguanine derivatives was also examined. For the tautomerization syn-G(N2-H)$)^{\bullet} \rightarrow \mathrm{G}(\mathrm{N} 1-\mathrm{H})^{\bullet}\left(\mathrm{R}=2^{\prime}\right.$-deoxyribose), the same behavior is observed with an identical rate constant $\left(k=5.0 \times 10^{4} \mathrm{~s}^{-1}\right)$ when starting from 8-bromo-2'deoxyguanosine [11]. It is worth mentioning the redox reactions of guanine derivatives having methylation at the $\mathrm{N} 1$ position: the oxidation of 1-methyl guanosine (1-Me-Guo, 7) by $\mathrm{Br}_{2}{ }^{\bullet-}$ and the reduction of 8-Br-1-Me-Guo (9) by $\mathrm{e}_{\mathrm{aq}}{ }^{-}$showed identical absorption spectra having a band at 610-620 nm, which decays via second-order kinetics (Figure 4). The transient is consistent with the 1-Me-G(N2-H) ${ }^{\bullet}$ radical (8) and the absence of tautomerization due to the N1-Me group $[11,28]$. The ESR and UV-visible spectra of 1-Me-G ${ }^{\bullet+}$ and its corresponding deprotonated 1-Me-G(N2-H) ${ }^{\bullet}$ are also recorded from the one-electronoxidized 1-Me-dGuo by $\mathrm{Cl}_{2}{ }^{--}$at $77 \mathrm{~K}$ at $\mathrm{pDs} \sim 5$ and $\sim 8$ in $7.5 \mathrm{M}$ of $\mathrm{LiCl}$ glass $/ \mathrm{D}_{2} \mathrm{O}$, 
respectively [30]. Identical spectra were observed in the deoxyribose derivative, and the distinction of syn- and the anti-conformation is not possible experimentally [30].

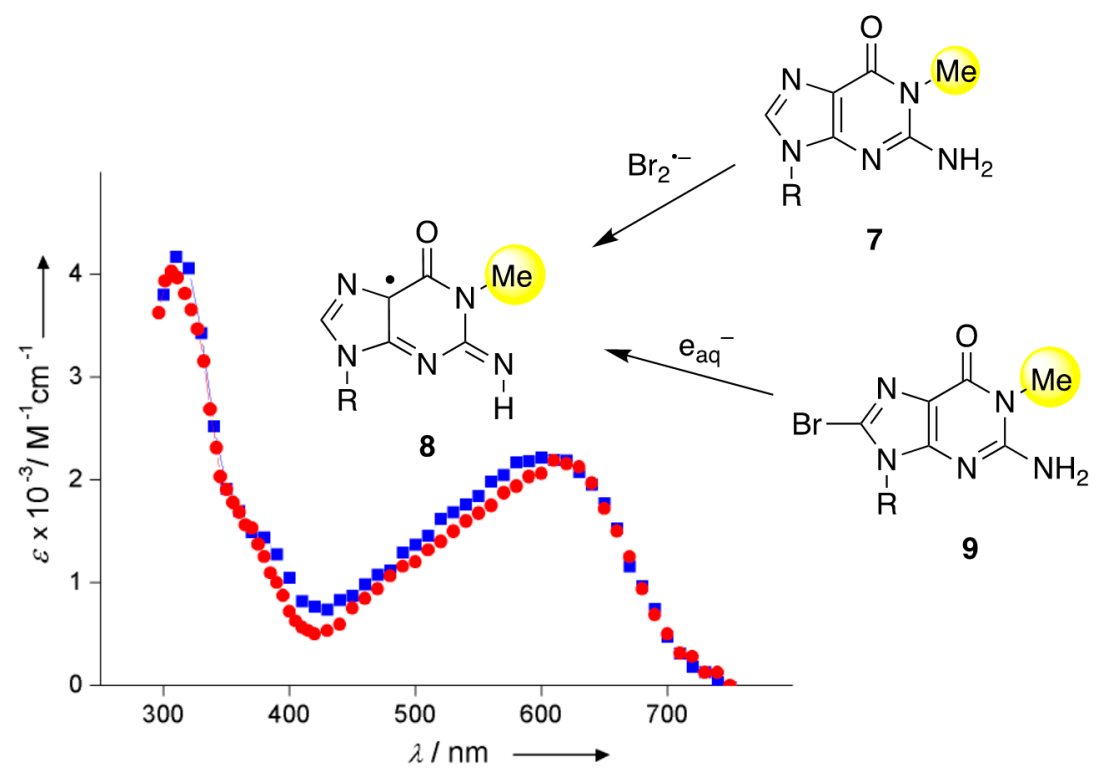

Figure 4. Absorption spectrum (red circles) refers to the oxidation of $7 \mathrm{by}^{\mathrm{Br}}{ }^{\bullet-}$ and is assigned to the $\mathrm{G}(\mathrm{N} 2-\mathrm{H})^{\bullet}$ radical (8); for the $\varepsilon$ values, $\mathrm{G}_{\left(\mathrm{Br}_{2}\right.}{ }^{\bullet-}$ ) $=0.62 \mu \mathrm{mol} \mathrm{J}{ }^{-1}$ was assumed (taken from [14]). The absorption spectrum (blue square) refers to the reduction of $9 \mathrm{by} \mathrm{e}_{\mathrm{aq}}{ }^{-}$and is assigned to the same $\mathrm{G}(\mathrm{N} 2-\mathrm{H})^{\bullet}$, having presumably the syn-conformation; for the $\varepsilon$ values, $G\left(\mathrm{e}_{\mathrm{aq}}{ }^{-}\right)=0.27 \mu \mathrm{mol} \mathrm{J}$ was assumed (taken from [28]). See Appendix A for radiation chemical yields.

A thorough comparative computational analysis on the absorption spectra of three guanine-derived radicals (i.e., $\mathrm{G}^{\bullet+}, \mathrm{G}(\mathrm{N} 1-\mathrm{H})^{\bullet}$, and syn-G(N2-H)$)^{\bullet}$ ) in the methyl guanine model was recently reported, indicating that the use of five water molecules of the first solvation shell, the Polarizable Continuum Model (PCM) by TD-DFT based approaches, and the incorporation of vibronic effects provide a good agreement between experiments and theory [31]. The substitution in position 9 of hydrogen in guanosine with a methyl group produces small but noticeable changes in the spectra.

\section{Reaction of Hydroxyl Radical with Guanine Derivatives}

The reduction potential of $\mathrm{HO}^{\bullet}$ is very high $(+2.73 \mathrm{~V}$ in acid media and $+1.90 \mathrm{~V}$ at $\mathrm{pH}$ 7), but the direct electron-transfer is still rarely observed in $\mathrm{HO}^{\bullet}$ reactions [13]. This is also the case for the reaction of $\mathrm{HO}^{\bullet}$ with guanine derivatives (1), where the redox properties are favorable for electron transfer but $\mathrm{H}$-atom abstraction and addition are observed.

The reactions of $\mathrm{HO}^{\bullet}$ with Guo or dGuo occur with rate constants of ca. $5 \times 10^{9} \mathrm{M}^{-1} \mathrm{~s}^{-1}$. An ambident reactivity has been observed for the reaction of $\mathrm{HO}^{\bullet}$ with the $\mathrm{G}$ moiety in aqueous medium. In 2000, it was reported that the addition to the base occurs at the C4 position $(\sim 65 \%)$ to give an adduct, which is the precursor of $\mathrm{G}(\mathrm{N} 1-\mathrm{H})^{\bullet}$ via a dehydration path and at the C8 position ( 17\%) [32]. The main path ( $\sim 65 \%)$ was based on the oxidizing properties of the transient species (toward TMPD with $k=\sim 2 \times 10^{9} \mathrm{M}^{-1} \mathrm{~s}^{-1}$ ). A few years later, the reaction was revisited by us finding that the main path $(\sim 65 \%)$ is represented by hydrogen abstraction from the exocyclic $\mathrm{NH}_{2}$ group affording $\mathrm{G}(\mathrm{N} 2-\mathrm{H})^{\bullet}$, the oxidizing species that is the precursor of $\mathrm{G}(\mathrm{N} 1-\mathrm{H})^{\bullet}$ via the tautomerization path $[27,33]$.

The revision was based on the results of a detailed pulse radiolysis with Guo (1) and 1-Me-Guo (7) and their bromo derivatives 8-Br-Guo (4) and 8-Br-1-Me-Guo (9) $[27,33]$. The absorption spectra for the reaction of $\mathrm{HO}^{\bullet}$ with $\mathbf{1}$ and $\mathbf{7}$ recorded $\sim 1 \mu$ s after the pulse are reported in Figure 5a,b (black), respectively. The same figures report the absorption spectra obtained from the reactions of $\mathrm{e}_{\mathrm{aq}}{ }^{-}$with 4 and 9 (red) described in the previous section. The $\varepsilon$ values of the black spectra arising from the reaction with $\mathrm{HO}^{\bullet}$ radicals 
were calculated using $\mathrm{G}=0.61 \mu \mathrm{mol} \mathrm{J}^{-1}$, as both $\mathrm{HO}^{\bullet}$ and $\mathrm{H}^{\bullet}$ species are scavenged by the guanosine derivatives (cf. Appendix A). On the other hand, both red spectra were calculated using $G=0.27 \mu \mathrm{mol} \mathrm{\textrm {J } ^ { - 1 }}$ of $\mathrm{e}_{\mathrm{aq}}{ }^{-}$, choosing a percentage of intensity of the corresponding species in order to match the maximum of the spectra around $600 \mathrm{~nm}$. The overlap in the range of $500-700 \mathrm{~nm}$ was excellent, choosing $65 \%$ and $55 \%$ for $\mathrm{G}(\mathrm{N} 2-\mathrm{H})^{\bullet}$ and $1-\mathrm{Me}-\mathrm{G}(\mathrm{N} 2-\mathrm{H})^{\bullet}$, respectively, suggesting that $\mathrm{HO}^{\bullet}$ radicals react $65 \%$ with Guo (Figure 6) and $55 \%$ with 1 -Me-Guo by $\mathrm{H}$-atom abstraction from the exocyclic $\mathrm{NH}_{2}$ group. The fate of the former is the tautomerization by pseudo-first-order kinetics $\left(k_{\text {taut }}=2.3 \times 10^{4} \mathrm{~s}^{-1}\right)$ to give the tautomer $\mathrm{G}(\mathrm{N} 1-\mathrm{H})^{\bullet}$, whereas the latter follows a second-order decay because the $\mathrm{N} 1$ position is blocked. The discussed spectra in the range of $500-700 \mathrm{~nm}$ do not contain the contribution from the $\mathrm{H}$-atom reactions, because the $\mathrm{H}$-atom adducts do not absorb at wavelengths above $500 \mathrm{~nm}$ [34]. The validation of this analysis is further confirmed when the exocyclic $\mathrm{NH}_{2}$ moiety is replaced by NHEt or $\mathrm{NEt}_{2}$; the tautomerization G(N2-H) ${ }^{\bullet}$ $\rightarrow \mathrm{G}(\mathrm{N} 1-\mathrm{H})^{\bullet}$ occurs only in the first case with a rate constant of $3.6 \times 10^{4} \mathrm{~s}^{-1}$, whereas, in the second case, a guanyl radical is not formed at all [27,33]. Furthermore, DFT-TD calculations strongly support the structural assignment, as no computed optical transitions were found for the $\mathrm{C} 4-\mathrm{OH}$ adduct of dGuo above $500 \mathrm{~nm}[27,33]$. The insets in Figure 5a,b show the corresponding difference between the two spectra. Both of them show a strong band around $300 \mathrm{~nm}$ and various smaller broad bands up to $500 \mathrm{~nm}$. These spectra are expected to be the sum of contributions from the $8-\mathrm{HO}$ and $8-\mathrm{H}$ adducts, as also predicted by the DFT-TD calculations $[27,33]$.

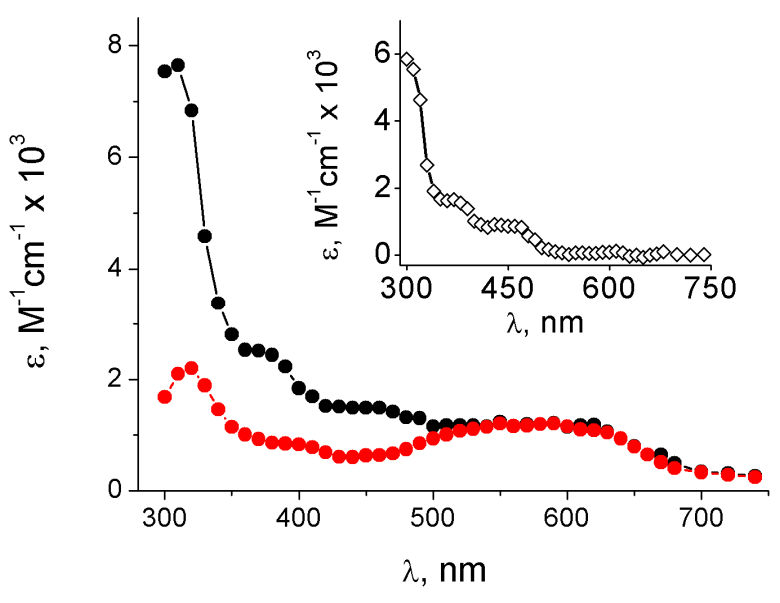

(a)

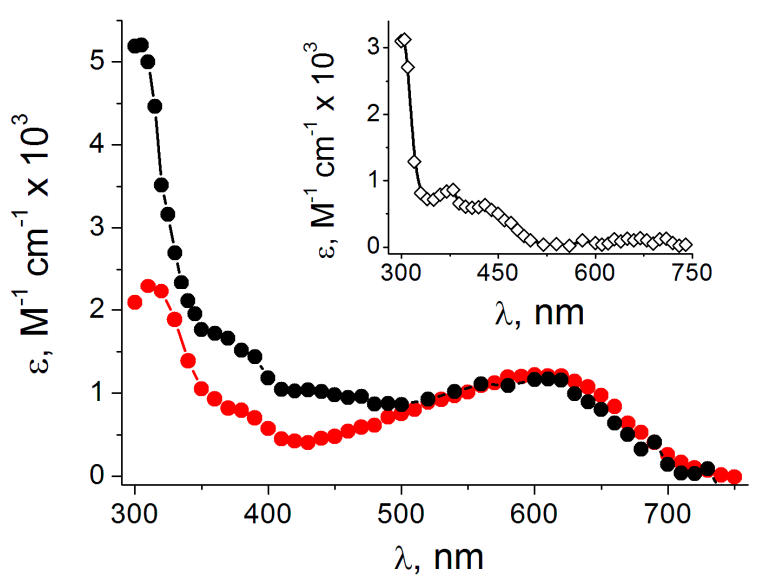

(b)

Figure 5. (a) Absorption spectra obtained from the reaction of $\mathrm{HO}^{\bullet}$ with Guo (1) recorded $1 \mu$ s (black) after the pulse and $65 \%$ of the intensity of the absorption spectra obtained from the reaction of $\mathrm{e}_{\mathrm{aq}}{ }^{-}$with 8-Br-Guo (4) recorded $1 \mu \mathrm{s}$ (red) after the pulse (inset: the spectrum resulting from the subtraction of red from black) (taken from [27]); (b) absorption spectra obtained from the reaction of $\mathrm{HO}^{\bullet}$ with 1-Me-Guo (7) recorded $1.2 \mu$ s (black) after the pulse and 55\% of the intensity of the absorption spectra obtained from the reaction of $\mathrm{e}_{\mathrm{aq}}{ }^{-}$with 8-Br-1-Me-Guo (9) recorded $10 \mu \mathrm{s}$ (red) after the pulse (inset: the spectrum resulting from the subtraction of red from black) (taken from [33]). 


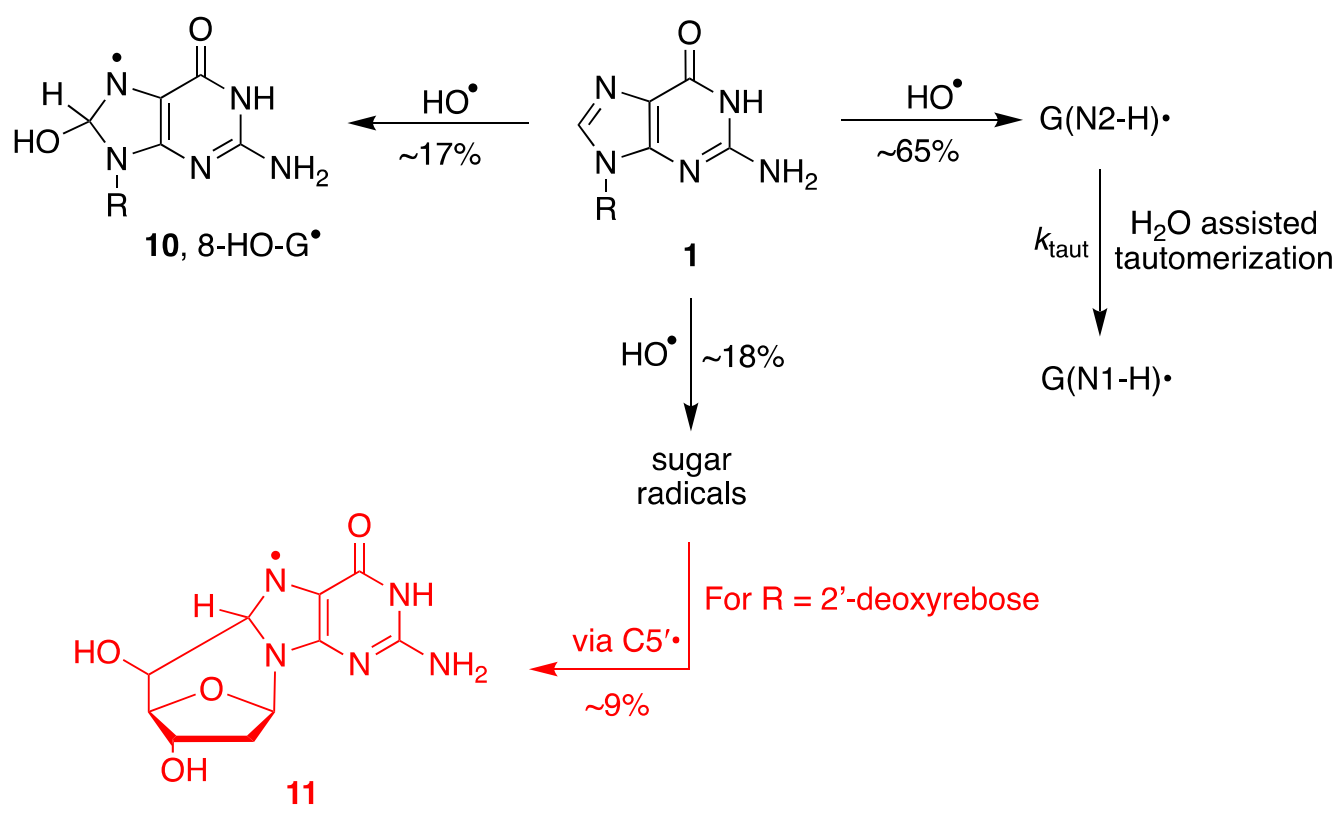

Figure 6. Reaction of $\mathrm{HO}^{\bullet}$ with guanine moiety of $\mathbf{1}$ in aqueous medium. The main path $(\sim 65 \%)$ is the $\mathrm{H}$-atom abstraction from the exocyclic $\mathrm{NH}_{2}$ group to give $\mathrm{G}(\mathrm{N} 2-\mathrm{H})^{\bullet}$ followed by water-assisted tautomerization $\mathrm{G}(\mathrm{N} 1-\mathrm{H})^{\bullet}$. The two minor paths are the addition at the $\mathrm{C} 8$ position giving the adduct $10(\sim 17 \%)$ and the hydrogen abstraction from the sugar moiety $(\sim 18 \%)$. When $\mathrm{R}=2^{\prime}$-deoxyrebose, about half of the $\mathrm{H}$-atom abstraction from the sugar occurs at the $\mathrm{H}^{\prime}$ positions, followed by cyclization with the formation of radical 11 (adapted from [33]).

It is also worth mentioning the substitution effect at the C8 position [33]. By replacing the hydrogen of $\mathrm{C} 8-\mathrm{H}$ by an alkyl group, the rate constant of tautomerization is similar $\left(3.0 \times 10^{4} \mathrm{~s}^{-1}\right)$, whereas a 15-fold increase is observed by replacing $\mathrm{H}$ with $\mathrm{Br}$ $\left(3.6 \times 10^{5} \mathrm{~s}^{-1}\right)$. It is worth underlining that the rate constant of tautomerization is found to be 2 times slower than that reported for the reaction of bromo-derivative 4 in Figure 3. The difference in experimental conditions $\left(\mathrm{N}_{2} \mathrm{O}\right.$-saturated aqueous solutions vs. Ar-purged aqueous solutions and $0.25 \mathrm{Mt}-\mathrm{BuOH}$ at $\mathrm{pH} 7$ ) and, more importantly, the overlap of various transient spectra in the reaction of $\mathrm{HO}^{\bullet}$ may be the origin of such a difference.

The overall mechanism for the reaction of $\mathrm{HO}^{\bullet}$ with Guo and dGuo is illustrated in Figure 6, with the main path $(\sim 65 \%)$ being the $\mathrm{H}$-atom abstraction from the $\mathrm{NH}_{2}$ group and the two minor paths, the formation of the adduct radical $10(17 \%)$ and the H-atom abstraction from the sugar moiety $(\sim 18 \%)[27,33]$. A half percentage of this latter path occurs at the $\mathrm{H}^{\prime}$ positions and, in the dGuo case, is followed by radical cyclization with the formation of cyclo-derivative $\mathbf{1 1}[33,35]$.

It is worth mentioning that time-resolved optical transient absorption spectra for the reaction of $\mathrm{HO}^{\bullet}$ with guanine (Gua, free base) was investigated using the pulse radiolysis technique [36]. The reaction was performed at $\mathrm{pH} 4.6$ in order to have mainly the neutral molecule (Gua has three $\mathrm{p} K_{\mathrm{a}}$ values: 3.3, 9.4, and 12.4). The transient absorption spectra were different from those reported for the reaction of $\mathrm{HO}^{\bullet}$ with dGuo and Guo, with the $620 \mathrm{~nm}$ band particularly being absent. On the basis of the spectral characteristics, reactivity, and quantum chemical calculations, the absorbing species at 330 and $300 \mathrm{~nm}$ have been assigned to the $\mathrm{C} 4-\mathrm{OH}$ and $\mathrm{C} 8-\mathrm{OH}$ adducts, respectively [36]. Indeed, a significant difference (more than $200 \mathrm{mV}$ ) exists between the oxidation potentials of Gua and Guo or $\mathrm{dGuo}$, where the $\pi$ electrons play a significant role in the oxidation process, together with the lone electron pair on N9 in the case of the unsubstituted imidazole ring [37]. The reaction of $\mathrm{HO}^{\bullet}$ with Gua in an aqueous environment is also addressed by density functional theory (B3LYP) [38]. The calculations suggested the formation of an ion-pair intermediate $\left(\mathrm{G}^{\bullet+}-\mathrm{OH}^{-}\right)$that deprotonates to form $\mathrm{H}_{2} \mathrm{O}$ and a neutral $\mathrm{G}$ radical, favoring $\mathrm{G}(\mathrm{N} 1-\mathrm{H})^{\bullet}$ over $\mathrm{G}(\mathrm{N} 2-\mathrm{H})^{\bullet}$. The CAM-B3LYP calculation of their UV-visible spectra predicted an absorption around $620 \mathrm{~nm}$ [38], which is in contrast with the mentioned experimental 
results [36]. The theoretical work on the reaction of $\mathrm{HO}^{\bullet}$ with $\mathrm{Gua}$ [38], often used as a reference for the reaction of the $\mathrm{HO}^{\bullet}$ radical with Guo or dGuo or even DNA, is not appropriate. Dizdaroglu in two reviews of 2012 collected and discussed the reactivity of $\mathrm{HO}^{\bullet}$ with guanine derivatives without taking into consideration the guanine moiety in different molecular contexts, such as Gua vs. dGuo, and they erroneously questioned the mechanism reported in Figure $6[39,40]$.

\section{Photochemical Precursors}

An alternative approach for guanyl radical generation is based on the photolabile modifier of the guanine moiety. Synthetic precursors 12 and $\mathbf{1 3}$ ( $\mathrm{R}=$ deoxyribose) were designed to generate $\mathrm{G}(\mathrm{N} 1-\mathrm{H})^{\bullet}$ through the homolysis of the $\mathrm{N}-\mathrm{O}$ bond, and compound 14 was proposed for the selective photo-generation of $\mathrm{G}(\mathrm{N} 2-\mathrm{H})^{\bullet}$ (Figure 7). The G(N1-H) radical was confirmed for $\mathbf{1 2}$ by continuous photolysis product analysis and trapping studies in water, as well as laser flash photolysis experiments [41]. dGuo was formed quantitatively when the precursor $\mathbf{1 3}$ is photolyzed under anaerobic conditions in phosphate buffer $(\mathrm{pH}=7.2)$ and in the presence of an excess of $\beta$-mercaptoethanol [42].<smiles>[R]n1cnc2c(On3ccccc3=O)nc(N)nc21</smiles>

12<smiles>[R]n1cnc2c(ON3C(=O)c4cccc5cccc(c45)C3=O)nc(N)nc21</smiles>

13<smiles>[R]n1cnc2c(=O)[nH]c(NOC(C)(C)C(=O)C(C)(C)C)nc21</smiles>

14

Figure 7. Photochemical precursors $\mathbf{1 2}$ and $\mathbf{1 3}$ for the formation of $\mathrm{G}(\mathrm{N} 1-\mathrm{H})^{\bullet}$, and $\mathbf{1 4}$ for the formation of $\mathrm{G}(\mathrm{N} 2-\mathrm{H})^{\bullet}$.

Upon $355 \mathrm{~nm}$ laser flash photolysis of $14(1 \mathrm{mM})$ and acetophenone $(30 \mathrm{mM})$ in aqueous buffer ( $\mathrm{pH} 7.0)$ /acetonitrile $(1: 1, v / v)$, the formation of $\mathrm{G}(\mathrm{N} 2-\mathrm{H})^{\bullet}$ is proposed [43]. A broad band between 550 and $700 \mathrm{~nm}$ with a maximum at $650 \mathrm{~nm}$ was observed, and the authors hypothesized that the broad band contains peaks at 610 and $650 \mathrm{~nm}$ belonging to the different conformational isomers of $\mathrm{G}(\mathrm{N} 2-\mathrm{H})^{\bullet}$, in which the remaining $\mathrm{N}-\mathrm{H}$ bond is either syn or anti with respect to the guanine N3 atom (cf. Figure 2B). Under their experimental conditions, a variety of possible transients is possible and the observed spectra are an overlap of various species with an over-interpretation regarding the $\mathrm{G}(\mathrm{N} 2-\mathrm{H})^{\bullet}$ radical, which is probably present in a relative low percentage. Indeed, their recorded absorption spectra are in contrast with those reported previously, and no tautomerization was observed within hundreds of microseconds in these experiments. Based on these questionable results, it was suggested that the hydrogen atom abstraction from dG is unlikely to be a major pathway when $\mathrm{HO}^{\bullet}$ reacts with dG (see Figures 5 and 6) [43]. Additionally, these authors did not consider that $\mathrm{H}_{2} \mathrm{O}$-assisted tautomerization depends on the solvent-composition. Water or phosphate buffer ( $\mathrm{pH} 7.0)$ is not equivalent to the mixture aqueous buffer $(\mathrm{pH}$ $7.0)$ /acetonitrile $(1: 1, v / v)$. The microheterogeneities of water-acetonitrile mixtures are well documented (see e.g., refs [44-46]). The independent generation of the G(N2-H) ${ }^{\bullet}$ radical by photochemical precursors for time-resolved spectroscopic studies needs to be addressed by further research.

\section{The Fate of Guanyl Radical in Nucleosides}

As shown above, guanine can be oxidized to $\mathrm{G}^{\bullet+}$ by a variety of oxidants such as $\mathrm{SO}_{4}^{\bullet-}, \mathrm{Br}_{2}^{\bullet-}, \mathrm{Cl}_{2}^{\bullet-}$, and $\mathrm{CO}_{3}^{\bullet-}$, including various metal complexes. The carbonate radical anion $\left(\mathrm{CO}_{3}{ }^{-}\right)$is an important reactive species under physiological conditions. The pair $\mathrm{CO}_{2} / \mathrm{HCO}_{3}{ }^{-}$is an active buffer maintaining physiological $\mathrm{pH}$, and $\mathrm{HCO}_{3}{ }^{-}$exists 
in millimolar levels in vivo. The reaction of $\mathrm{CO}_{2}$ with peroxynitrite $\left(\mathrm{ONOO}^{-}\right)$generates $\mathrm{CO}_{3}{ }^{\bullet-}$ through the unstable nitrosoperoxycarbonate [47]. The reaction of $\mathrm{HO}^{\bullet}$ with $\mathrm{HCO}_{3}{ }^{-}$ produces $\mathrm{CO}_{3}{ }^{\bullet}$. The Fenton reaction in the presence of $\mathrm{HCO}_{3}{ }^{-}$affords $\mathrm{CO}_{3}{ }^{\bullet-}$ rather than the $\mathrm{HO}{ }^{\bullet}$ radical [48]. The reduction potential of $\mathrm{CO}_{3}{ }^{\bullet}-/ \mathrm{CO}_{3}$ is $1.59 \mathrm{~V}$; therefore, $\mathrm{CO}_{3}{ }^{\bullet-}$ is a milder single-electron oxidant that abstracts an electron from guanine moieties [49]. The oxidation mechanism and kinetics of dGuo (1) by the carbonate radical anion $\left(\mathrm{CO}_{3}{ }^{\bullet-}\right)$ have also been investigated theoretically [50].

The iron-induced Fenton oxidation of dGuo (1) in the presence of bicarbonate buffer and in its absence (phosphate buffer) affords different distribution products consistent with $\mathrm{CO}_{3}{ }^{\bullet-}$ and $\mathrm{HO}{ }^{\bullet}$ reactive intermediates, respectively [51]. Figure 8 shows the overall mechanism of oxidation of dGuo by $\mathrm{HO}^{\bullet}$ and $\mathrm{CO}_{3}{ }^{\bullet-}$. The two oxidants have some common intermediates generated by different routes, e.g., (N1-H) ${ }^{\bullet}$ and $8-\mathrm{HO}-\mathrm{G}^{\bullet}$ radicals. The $8-\mathrm{HO}-\mathrm{G}^{\bullet}$ is the common precursor of 8-oxo-G and Fapy-G. The Fapy-G formation requires ring-opening followed by one-electron reduction or vice versa (i.e., one-electron reduction followed by ring-opening). The formation of Fapy-G depends on the oxygen concentration and the redox environment $[52,53]$. 8-oxo-G, with a reduction potential $0.55 \mathrm{~V}$ lower than that of G [54], undergoes further oxidation in the presence of one-electron oxidants. Two main products derive from the oxidation of 8-oxo-G, namely spiroiminodihydantoin (Sp) and 5-guanidinohydantoin-2'-deoxyribose (Gh) [55]. From the oxidation of dGuo under aerobic conditions or in the presence of $\mathrm{CO}_{3}{ }^{\bullet}$, two other products are formed via $\mathrm{C} 5$ paths (Figure 8), viz. 5-carboxamido-5-formamido-2- iminohydantoin-2'-deoxyribonucleoside (2Ih) and 2-amino-5-[2-deoxyribose]-4H-imidazol-4-one (Iz). The latter is further hydrolyzed to 2,2-diamino-4-[(2-deoxyribose)amino]-5(2H)-oxazolone (Z) [56,57].

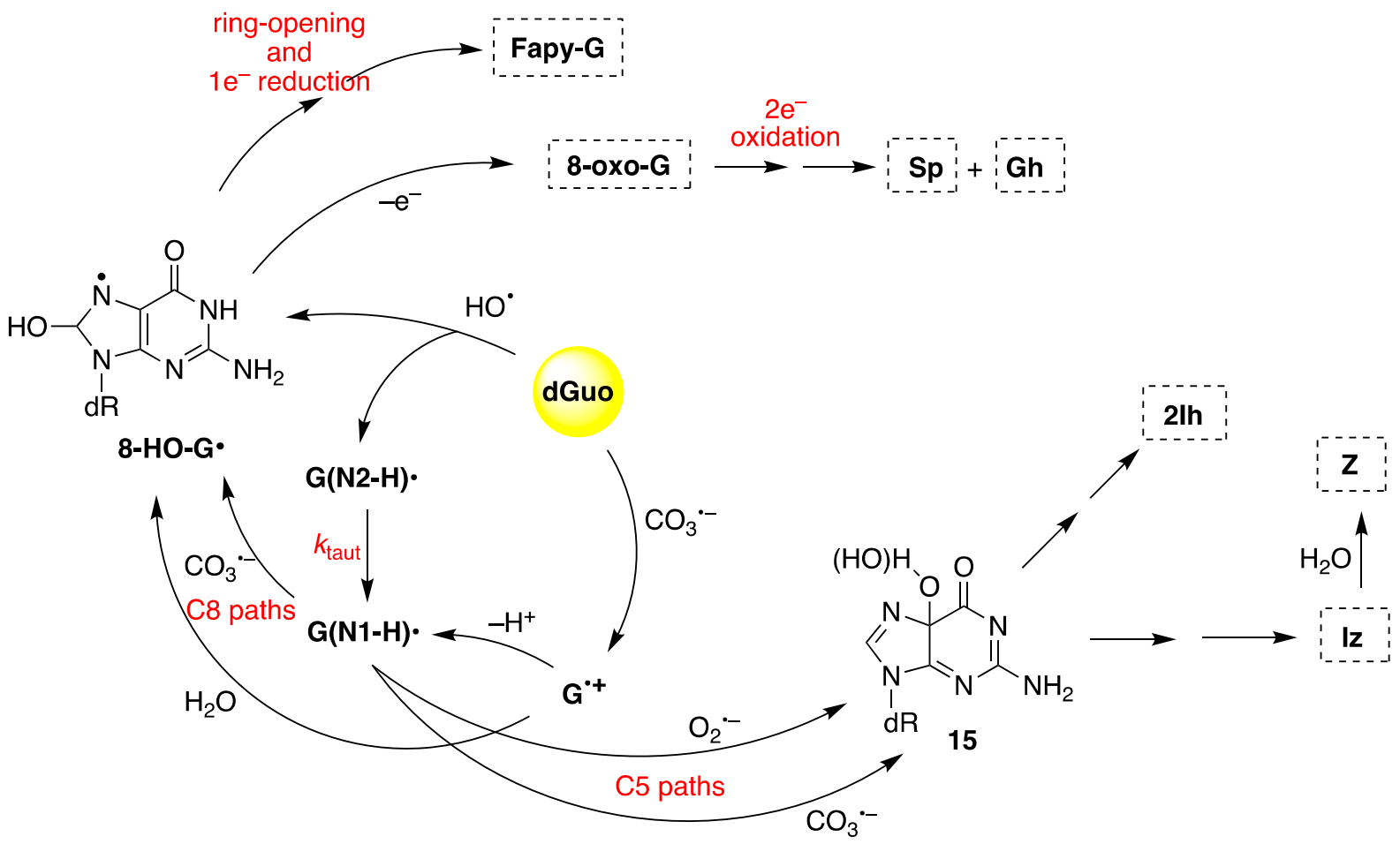

Figure 8. The mechanism of dGuo (1) oxidation by hydroxyl radical $(\mathrm{HO} \bullet)$ or carbonate radical anion $\left(\mathrm{CO}_{3}^{\bullet-}\right)$; for the chemical structures of 8-oxo-G, Fapy-G, Sp, Gh, 2Ih, Iz, and Z, see Figure 15.

\section{Guanyl Radicals in ss-ODNs and ds-ODNs}

The mode of formation and the kinetics of decay of $\mathrm{G}^{\bullet+}$ depend strongly on ODN secondary structures. In this section, we consider ss- and ds-ODNs, whereas the ODNs arranged in G-quadruplexes are reported in the next section. 
The one-electron oxidation of ss-ODN (TCGCT) by $\mathrm{CO}_{3}^{\bullet-}$ and $\mathrm{SO}_{4}^{\bullet-}$ was studied by laser flash photolysis in some detail [58]. Both reactions lead to the formation of the guanine radical cation $\mathrm{G}^{\bullet+}$ and/or its deprotonation product $\mathrm{G}(\mathrm{N} 1-\mathrm{H})^{\bullet}$ depending on $\mathrm{pH}$ $\left(\mathrm{p} K_{\mathrm{a}}=3.9\right)$ (Figure 9). At $\mathrm{pH} 2.5$, the $\mathrm{G}^{\bullet+}$ radical is hydrated within $3 \mathrm{~ms}$, forming 8-oxo-dG in the ODN. At $\mathrm{pH} 7.0, \mathrm{G}(\mathrm{N} 1-\mathrm{H})^{\bullet}$ reacts only slowly with $\mathrm{H}_{2} \mathrm{O}$ and lives for $\sim 70 \mathrm{~ms}$, ultimately giving intrastrand cross-link adducts. Alternatively, it can be further oxidized by reaction with $\mathrm{CO}_{3}{ }^{\bullet-}$, generating the two-electron oxidation products 8-oxo-dG (via C8 addition 16) and $2 \mathrm{Ih}$ (via $C 5$ addition 17). The same group has studied the one-electron oxidation of a 30mer ss-ODN containing eleven Gs in comparison with the same strand in ds-ODN, and these results are discussed below.

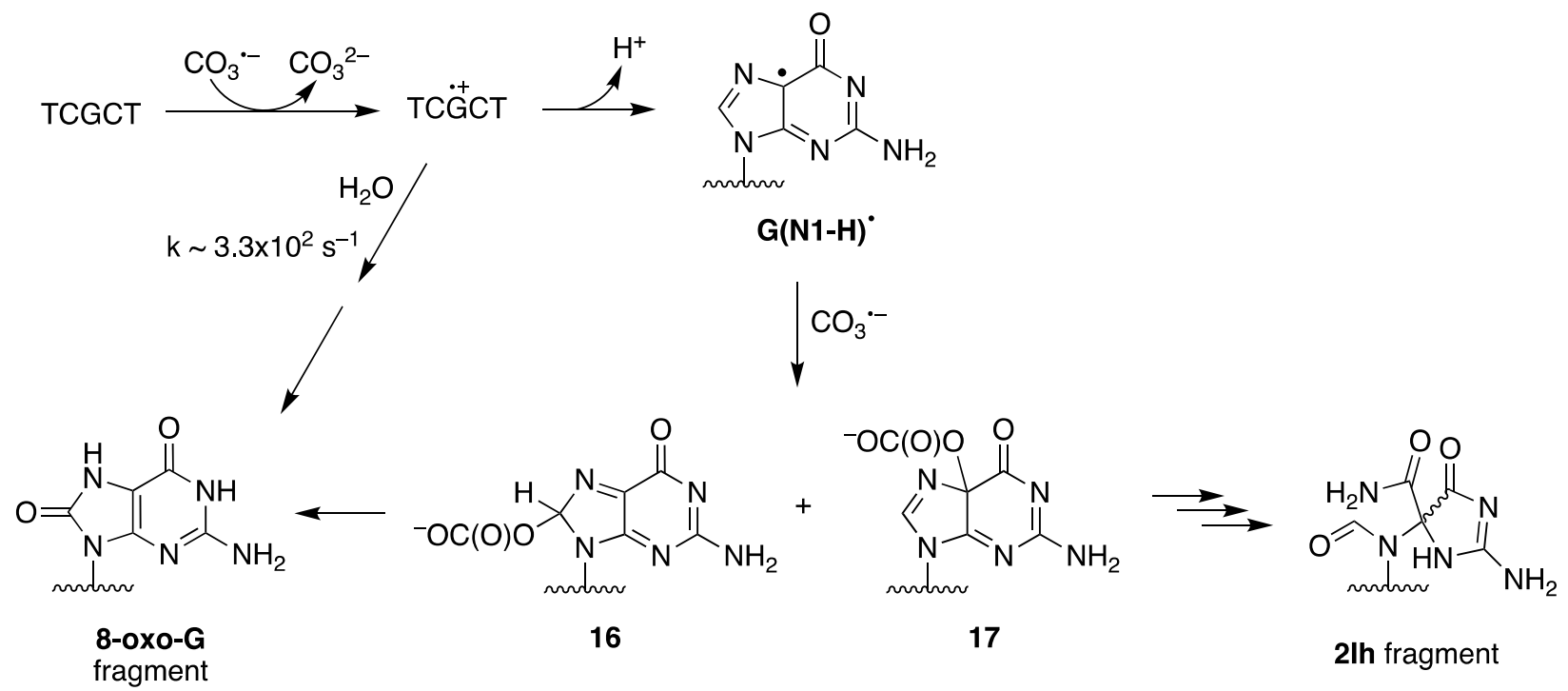

Figure 9. Mechanistic scheme of one-electron oxidation of ss-ODN (TCGCT) by carbonate radical anion $\mathrm{CO}_{3}{ }^{\bullet-}\left(\right.$ adapted $^{-}$ from ref. [54].

Since early works, it has been postulated that in DNA, the proton is not directly lost from $G^{\bullet+}$ to the aqueous phase but remains within the hydrogen-bonded $G^{\bullet+}:: C$ pair located toward the cytosine N3 atom [12]. ESR studies of the one-electron oxidation of a variety of ds-ODNs indicated that the proton is entirely transferred $\left[\mathrm{G}(\mathrm{N} 1-\mathrm{H})^{\bullet}:: \mathrm{CH}^{+}\right]$ at $77 \mathrm{~K}[59]$, whereas a prototropic equilibrium $\left[\mathrm{G}^{\bullet+}:: \mathrm{C} \leftrightarrows \mathrm{G}(\mathrm{N} 1-\mathrm{H})^{\bullet}::: \mathrm{CH}^{+}\right]$should be established at ambient temperature. Most of the experimental studies described below on ds-ODNs used $\mathrm{SO}_{4}{ }^{\bullet-}$ as the oxidizing agent. It should be recalled that $\mathrm{SO}_{4}{ }^{\bullet-}$ reacts with all four nucleobases (G, C, A, and T) with rate constants that are close to diffusion-controlled rates [13], although the primary damage is localized at Gs, having the lowest reduction potential (cf. Section 1) [4-10].

The one-electron oxidation by the powerful $\mathrm{SO}_{4}{ }^{\bullet-}$ of a variety of ds-ODNs containing G:::C pairs has been reported in pulse radiolysis [16,60] or laser flash photolysis [61] studies. Pulse radiolysis with optical detection showed that different ds-ODNs containing G, GG, and GGG sequences afford the corresponding radical cation $\mathrm{G}^{\bullet+}:: \mathrm{C}$. In the earlier work [16], a biphasic decay of $\mathrm{G}^{+\bullet}:: \mathrm{C}$ was assigned to the shift in the $\mathrm{N} 1$ proton in $\mathrm{G}^{+\bullet}$ to its partner $\mathrm{C}$, followed by the release of the proton into the solution. The same group revisited these reactions by analyzing the optical spectra and the kinetics of eleven ds-ODNs with different sequences (11mer to 13 mer ds-ODNs) [60]. The revised results concern the monophasic decay of $\left[\mathrm{G}^{\bullet+}: .: \mathrm{C} \leftrightarrows \mathrm{G}(\mathrm{N} 1-\mathrm{H})^{\bullet}: .: \mathrm{CH}^{+}\right]$associated with the release of the proton into solution. Based on $p K_{\mathrm{a}}$ values, the population of positive charges is estimated to be $\sim 1: 3$ in favor of cytosine [12]. The rate constant for deprotonation was dependent on the ds-ODN sequence, especially on the sequence of bases adjacent to the guanine base, varying in the range of $0.3-2 \times 10^{7} \mathrm{~s}^{-1}$ by monitoring the transient. In the ds-ODN of the $13 m e r \mathrm{~A}_{5} \mathrm{G}_{3} \mathrm{~A}_{5}$, the first transient decays with $k=4.5 \times 10^{6} \mathrm{~s}^{-1}$ in $\mathrm{H}_{2} \mathrm{O}$, showing a $k\left(\mathrm{H}_{2} \mathrm{O}\right) / k\left(\mathrm{D}_{2} \mathrm{O}\right)$ of 
3.8-fold. Interestingly, by replacing $\mathrm{C}$ with 5 -Me-C or 5-Br-C in ds-ODN, the rate constant of deprotonation increased or decreased, respectively. Overall, the proposed mechanism consists of path A in Figure 10 [60].

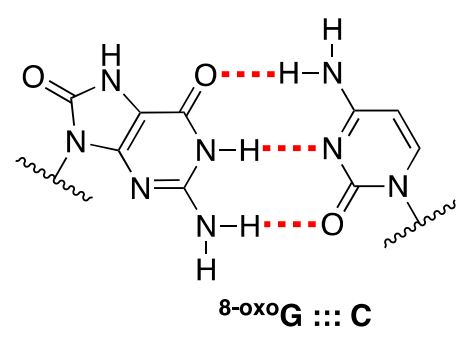

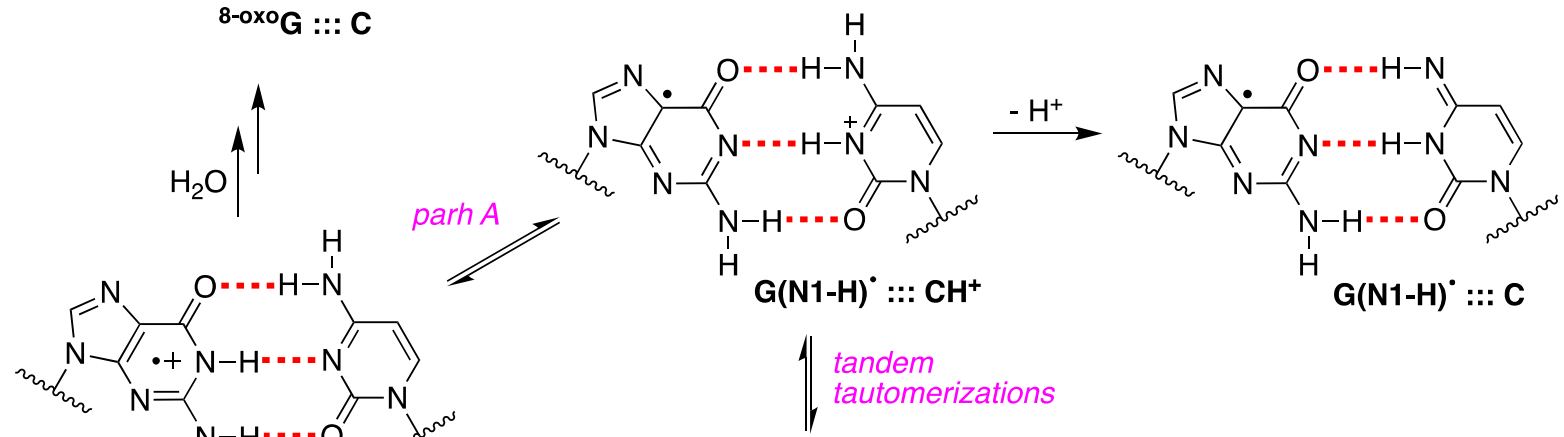

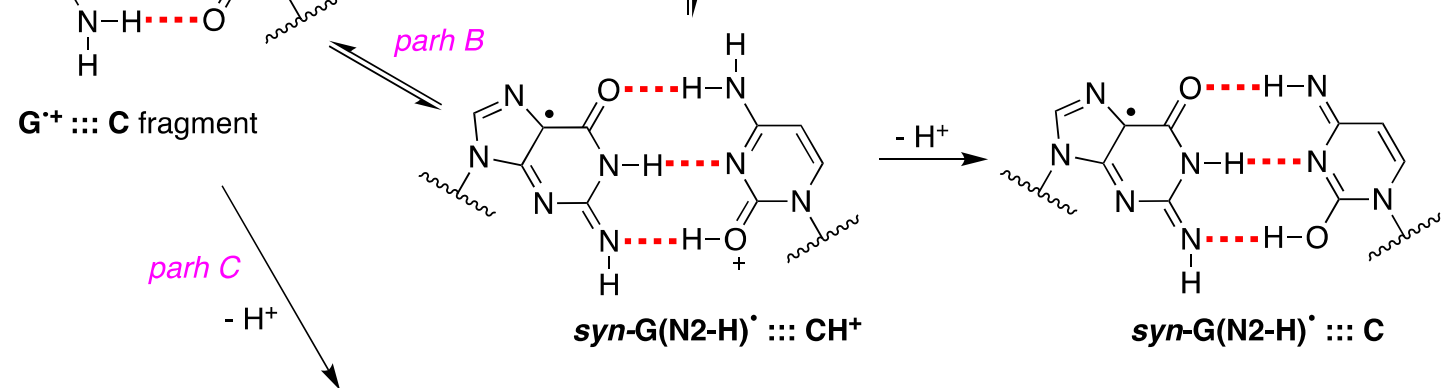<smiles></smiles>

anti-G(N2-H) ::: C

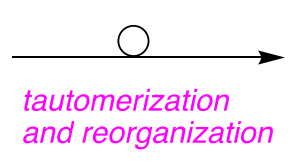

and reorganization

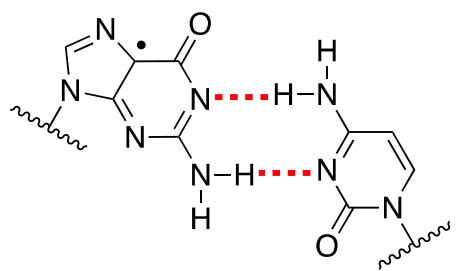

G(N1-H) ::: C'

Figure 10. Mechanistic possibilities of $\mathrm{G}^{\bullet+}:: \mathrm{C}$ deprotonation in ds-ODNs and its reaction with water to give ${ }^{8-o x o} \mathrm{G}::: \mathrm{C}$.

Upon our discovery of the first directly observed differences of the two tautomeric forms of one-electron-oxidized Guo or dGuo (see Figure 3), we proposed that an alternative scenario of $\mathrm{G}^{\bullet+}:: \mathrm{C}$ deprotonation involving the tautomer $\mathrm{G}(\mathrm{N} 2-\mathrm{H})^{\bullet}$ should also be considered in future studies; in particular, using time-resolved studies, the monitoring of the absorbance changes around $620 \mathrm{~nm}$ is important, as $\mathrm{G}(\mathrm{N} 2-\mathrm{H})^{\bullet}$ has a distinct absorption [11]. Figure 10 shows the proposed paths B and $C$ that involve syn-G(N2-H) ${ }^{\bullet}$ and anti-G(N2$\mathrm{H})^{\bullet}$, respectively (cf. Figure 2B). In path $\mathrm{C}$, the protons can escape directly into the bulk solution forming anti-G(N2-H)$)^{\bullet}$, whereas, in path B, a proton-transfer equilibrium involves the syn-G(N2-H) ${ }^{\bullet}$ conformer that is calculated to be more stable. We were occasionally criticized for such a proposal, but, today, it is gratifying to see that such a "second face" of the guanyl radical, i.e., $\mathrm{G}(\mathrm{N} 2-\mathrm{H})^{\bullet}$, is indeed recalled as an intermediate in several oxidation reactions of secondary structures of DNA (vide infra).

For the first time, the presence of anti-G(N2-H) ${ }^{\bullet}:: \mathrm{C}$ in a ds-ODN is shown to be easily distinguished from the other prototropic forms, owing to its readily observable nitrogen hyperfine coupling by electron spin resonance (ESR) [30]. Indeed, the one-oxidation of $\mathrm{d}$ [TGCGCGCA $]_{2}$ has been studied in detail by ESR and UV-visible spectral analysis; 
at $\mathrm{pH} \geq 7$, the initial site of deprotonation is found to be at $\mathrm{N} 1$, forming $\mathrm{G}(\mathrm{N} 1-\mathrm{H})^{\bullet}:: \mathrm{C}$ at $155 \mathrm{~K}$, and upon annealing to $175 \mathrm{~K}$, the site of deprotonation to the solvent shifts to an equilibrium mixture of $\mathrm{G}(\mathrm{N} 1-\mathrm{H})^{\bullet}:: \mathrm{C}$ and anti-G(N2-H) ${ }^{\bullet}:: \mathrm{C}$. This ESR identification is supported by the visible absorption at $630 \mathrm{~nm}$, which is characteristic for $\mathrm{G}(\mathrm{N} 2-\mathrm{H})^{\bullet}$ radicals.

The one-electron oxidation of 30mer ODNs by $\mathrm{SO}_{4}{ }^{\bullet-}$, shown in Figure 11, was studied in ss-ODNs or ds-ODN by time-resolved absorption spectroscopy and quantification of the 8-oxo-G lesion as the final product [61]. Figure 11 shows the dependence of the yields of 8-oxo-dG in ds-ODN vs. ss-ODNs on the number of successive $308 \mathrm{~nm}$ laser pulses. The yield of 8-oxo-G in ds-ODN is $\sim 7$ times higher than that in ss-ODNs, and the initial 8 -oxo-G yields are $\sim 1 \mu \mathrm{M}$ per laser pulse that corresponds to $\sim 20 \%$ per $\mathrm{G}(-\mathrm{H})^{\bullet}$ radical generated. Therefore, the secondary structure of ds-ODN is a crucial factor that enhances the formation of 8-oxo-G lesions from G(N1-H) ${ }^{\bullet}$ radicals. The transient species observed after the complete decay of $\mathrm{SO}_{4}{ }^{--}(5 \mu \mathrm{s})$ for both ds-ODN and ss-ODN were very similar and assigned to $\mathrm{G}(\mathrm{N} 1-\mathrm{H})^{\bullet}$. However, the kinetics of $\mathrm{G}(\mathrm{N} 1-\mathrm{H})^{\bullet}$ decay were quite different; in ds-ODN, the decay is biphasic with one component decaying with a lifetime of $\sim 2.2 \mathrm{~ms}$ and the other one with a lifetime of $\sim 0.18 \mathrm{~s}$, whereas, in ss-ODN, the decay is monophasic with a $\sim 0.28 \mathrm{~s}$ lifetime. The millisecond decay component in ds-ODN is correlated with the enhancement of 8-oxo-G yields, which are $\sim 7$ times greater than those in ss-ODN. In ds-ODN, the authors proposed that the equilibrium $\left[\mathrm{G}^{\bullet+}:: \mathrm{C} \leftrightarrows \mathrm{G}(\mathrm{N} 1-\mathrm{H})^{\bullet}: .: \mathrm{CH}^{+}\right]$allows for the hydration followed by the formation of ${ }^{8-o x o} \mathrm{G}:: \mathrm{C}$ (see Figure 10). By contrast, in ss$\mathrm{ODN}$, the deprotonation of $\mathrm{G}^{\bullet+}$ and the irreversible escape of the proton into the aqueous phase compete more effectively with the hydration mechanism, thus diminishing the yield of 8-oxo-G. In order to accommodate the fast deprotonation (see above) [60], they invoked path $\mathrm{C}$ in Figure 10, followed by a tautomerization of G(N2-H) ${ }^{\bullet}$ to G(N1-H) coupled with base displacement and reorganization of the hydrogen-bonding network [61].

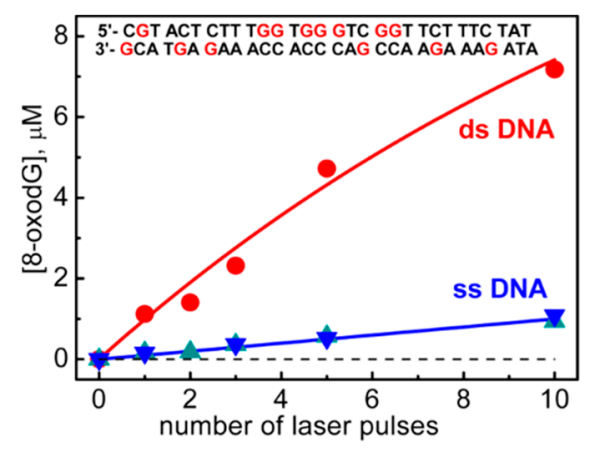

Figure 11. Dependence of the yields of 8-oxodGuo lesions in ds-ODN vs. ss-ODN on the number of successive $308 \mathrm{~nm}$ laser pulses. Taken from [58].

It was demonstrated that absorption of a single low-energy UV photon by ds-ODNs at $265 \mathrm{~nm}$ generates guanyl radicals, with an appreciable quantum yield $\left(>10^{-3}\right)$. The transient species detected after $3 \mu$ s are identified as guanyl radicals $\mathrm{G}(\mathrm{N} 1-\mathrm{H})^{\bullet}$, which decay with a half-life of $2.5 \mathrm{~ms}$. The experimental results corroborated by theoretical studies suggest nonvertical processes, associated with the relaxation of electronic excited states [62-64]. Similar results were obtained with ct-DNA [64]. The same ss-ODNs and ds-ODN reported in Figure 11 were studied by photoionization using ultra-purified chemicals [63]. Although the spectra on the microsecond timescale are the same as those reported [61], the radical lifetimes were found to be much shorter. It was also shown that base pairing slows down the radical lifetime, and this was attributed to the fact that larger conformational motions in single strands allow the systems to adopt more rapidly reactive conformations [63].

It is also worth citing the pulse radiolysis studies using the selenite radical, $\mathrm{SeO}_{3}{ }^{\bullet-}$ of $E^{0} 1.68 \mathrm{~V}$, oxidizing DNA with a rate constant of $3.5 \times 10^{7} \mathrm{M}^{-1} \mathrm{~s}^{-1}$ [65]. The oneelectron oxidation of ct-DNA by $\mathrm{SeO}_{3}{ }^{\bullet-}$ involves the G:::C pair in a different way, as it was proposed via a concerted formation of a cytosyl radical followed by proton loss from 
the amine substituent of cytosine into the major groove and the $\mathrm{H}$-atom transfer to the guanyl radical $\mathrm{G}(\mathrm{N} 1-\mathrm{H})^{\bullet}::: \mathrm{C}$ [65]. The neutral radical, anti-G(N2-H) $::: \mathrm{C}$, in DNA was formed directly through $\mathrm{H}$-atom abstraction from its amine moiety by the benzotriazinyl radical, and a DFT calculation corroborated such a pathway; the $E_{7}$ value of $1.22 \mathrm{~V}$ for anti-G(N2-H) ${ }^{\bullet::: C ~ h a s ~ b e e n ~ d e t e r m i n e d ~ b y ~ a n a l y s i s ~ o f ~ b o t h ~ a b s o r p t i o n ~ a n d ~ k i n e t i c ~ d a t a ~[66] . ~}$ Moreover, an investigation of the aniline radical cation, $\left(\mathrm{ArNH}_{2}\right)^{\bullet+}$, with ds-ODN or DNA suggested the formation of the guanyl radical in an energetically more stable "slipped" structure, similar to the one reported in Figure 10 (bottom-right) [67].

Much attention has been focused on computing the properties of the $G^{\bullet+}:: C$ pair fragment of DNA (e.g., the proton transfer equilibria, hydrated cation, tautomerism or redox behavior) by DFT calculations including solvent effects. The theoretical calculations have been abundant during the last two decades in this area, and it is not the scope of this review to examine the whole scenario of the reported calculations. Only a few with more attention on recent publications are reported; in particular, the influence of hydration on the proton transfer $\mathrm{G}^{\bullet+}:: \mathrm{C}$ pair [68-70]; the calculations for a single GC base pair, suggesting a very slight favor of anti-G(N2-H) ${ }^{\bullet}:: \mathrm{C}$ by $1.7 \mathrm{~kJ} \mathrm{~mol}^{-1}$ over the $\mathrm{G}(\mathrm{N} 1-\mathrm{H})^{\bullet}::: \mathrm{C}$ structure [30]; and the calculations providing reference absorption spectra for guanine radicals in duplexes and the computed spectra that predict changes in transient absorption spectra expected for hole localization, as well as for deprotonation (to cytosine and bulk water) and hydration of the radical cation [62,71].

It is worth mentioning that oxyl radicals such as $\mathrm{O}_{2}^{\bullet-}, \mathrm{NO}_{2}^{\bullet}$, and $\mathrm{CO}_{3}^{\bullet-}$ react with $\mathrm{G}(\mathrm{N} 1-\mathrm{H})^{\bullet}$ of ss-ODNs or ds-ODNs in cross-radical termination mode and, in all cases, the combination occurs via the analogous $\mathrm{C} 8$ and $\mathrm{C} 5$ paths reported in Figure 8 with the formation of expected end-products [72-74]. The ratio of the $\mathrm{C} 5 / \mathrm{C} 8$ products can depend on the macromolecular secondary structure, e.g., in the case of $\mathrm{NO}_{2}{ }^{\bullet}$, the ratio of $\mathrm{C} 5 / \mathrm{C} 8$ addition decreases from 2.1-2.6 in ss-ODNs to 0.8-1.1 in ds-ODNs [74]. The influence of the local base sequence and secondary structure on $\mathrm{G}$ oxidation by riboflavin-mediated photooxidation, and nitrosoperoxycarbonate with the formation of 8-oxo-G, Z, and 8- $\mathrm{NO}_{2}-\mathrm{G}$ lesions are also reported [75].

The radical chemistry reported for Guo or dGuo is often transferred to complex macromolecular arrangements such as the secondary DNA structure. From this section, it is clear that the one-electron oxidation of ds-ODNs or DNA is a complex matter with many variants, including chemical methods of generation, time-resolved spectroscopic approaches, base sequences, and thermochemical cascade. Mechanistic proposals are based on multidisciplinary knowledge, where DFT calculations can often help for a better understanding of the favored pathways but must be combined with the experimental evidence.

\section{Guanyl Radicals in G-Quadruplex}

The structure of the G-quadruplex consists of stacked G-quartets where each G-quartet is a planar array of four Hoogsteen-bonded guanines stabilized by metal cations [76]. The existence of $\mathrm{G}^{\bullet+}$ in the $\mathrm{G}$-quadruplex and their deprotonation from the $\mathrm{NH}_{2}$ moiety of guanines was first reported in a study performed via photosensitization (Figure 12A) [77]. The four G-quadruplexes buffered using $\mathrm{Na}^{+}$or $\mathrm{K}^{+}$, i.e., Tel22/ $\mathrm{Na}^{+}, \mathrm{TG} 4 \mathrm{~T} / \mathrm{K}^{+}, \mathrm{G} 4 \mathrm{~T} 4 \mathrm{G} 4 / \mathrm{Na}^{+}$, and the $\mathrm{TBA} / \mathrm{K}^{+}$, are used, that adopt three of them antiparallel and $\mathrm{TG} 4 \mathrm{~T} / \mathrm{K}^{+}$parallel orientations (see Figure 12B). The one-electron oxidation was carried out by $\mathrm{SO}_{4}{ }^{\bullet-}$ using laser flash photolysis for the transient detection. The deprotonation rate of $\mathrm{G}^{\bullet+}$ within $\mathrm{G}$-quadruplexes $\mathrm{Tel} 22 / \mathrm{Na}^{+}$, TG4T/K ${ }^{+}$, and G4T4G4/ $\mathrm{Na}^{+}\left(k=\sim 2 \times 10^{5} \mathrm{~s}^{-1}\right)$ was found to be $1-2$ orders of magnitude slower compared to $\mathrm{G}^{\bullet+}$ from dGuo or ds-ODNs with the formation of the $\mathrm{G}(\mathrm{N} 2-\mathrm{H})^{\bullet}$ radical in anti-conformation (Figure $\left.12 \mathrm{~A}\right)$, whereas in $\mathrm{TBA} / \mathrm{K}^{+}$, the deprotonation occurred from the $\mathrm{G}$ in the loop affording $\mathrm{G}(\mathrm{N} 1-\mathrm{H})^{\bullet}$ with a rate constant of $1.4 \times 10^{6} \mathrm{~s}^{-1}[77]$. 
(A)

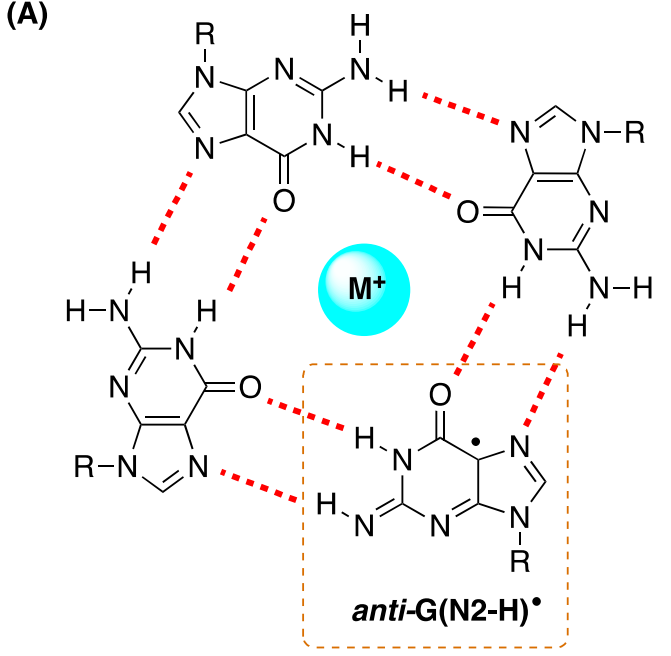

(B)

Telomeric sequences used in this review and their acronyms

Tel21 = GGG(TTAGGG) $)_{3}$

Tel22 $=$ AGGG $(\text { TTAGGG) })_{3}$

Tel24 = TTGGG(TTAGGG) ${ }_{3}$ A

Tel25 = TAGGG(TTAGGG) ${ }_{3}$ TT

Other molecular arrangements of G-quadruplex and their acronyms

$\mathrm{TG} 4 \mathrm{~T}=(\mathrm{TGGGGT})_{4}$ G4T4G4 $=(\text { GGGGTTTTGGGG })_{2}$ TBA = GGTTGGTGTGGTTGG

(C)

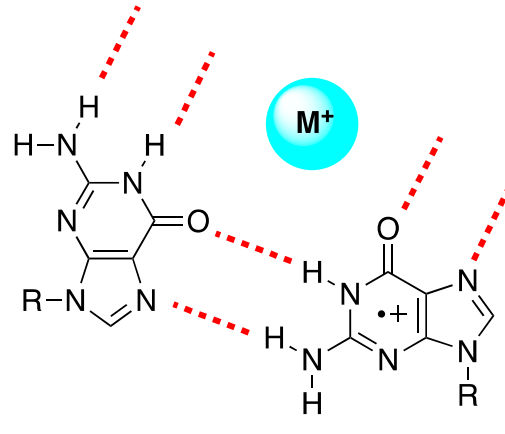

$G:: G^{*+}$

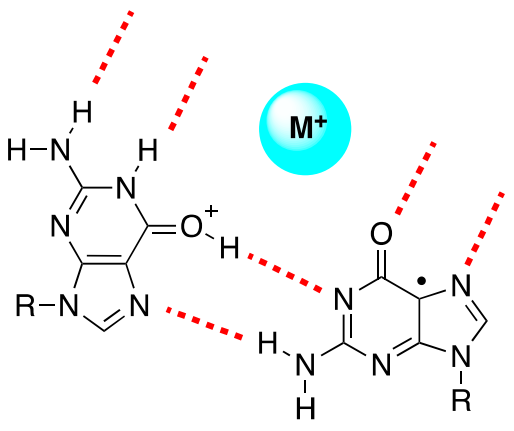

$\mathrm{GH}^{+}::: \mathrm{G}(\mathrm{N} 1-\mathrm{H})^{\cdot}$

Figure 12. (A) Drawing of G-quartet containing the guanyl radical anti-G(N2-H) ${ }^{\bullet}$ (cf. Figure 2B); (B) the ss-ODNs sequences used in this review (Sections 9 and 10) in G-quadruplex structures; (C) fragments of G-quartet; the proposed equilibrium in one-electron-oxidized G quartet [78].

In antithesis with the above-mentioned work [77], the one-electron oxidation of Tel25, buffered using $\mathrm{Na}^{+}$or $\mathrm{K}^{+}$, by $\mathrm{SO}_{4}{ }^{\bullet-}$ was also investigated by time-resolved spectroscopy and determined the end-product 8-oxo-G. In neutral aqueous solutions ( $\mathrm{pH} 7.0)$, the observed transient is $\mathrm{G}(\mathrm{N} 1-\mathrm{H})^{\bullet}$ after the complete decay of $\mathrm{SO}_{4}{ }^{\bullet-}(\sim 10 \mu$ s after the actinic laser flash). In both systems, the $\mathrm{G}(-\mathrm{H})^{\bullet}$ decay is biphasic with one component decaying with a lifetime of $\sim 0.1 \mathrm{~ms}$, and the other one with a lifetime of 20-30 ms. The fast decay component ( $\sim 0.1 \mathrm{~ms})$ in G-quadruplexes is correlated with the formation of 8-oxo-G lesions. The authors proposed that in G-quadruplexes, $\mathrm{G}(-\mathrm{H})^{\bullet}$ radicals retain their radical cation character by sharing the N1-proton with the O6-atom of $\mathrm{G}$ in the $\left[\mathrm{G}^{\bullet+}: . \mathrm{G}\right]$ Hoogsteen base pair (Figure 12C); this equilibrium $\left[\mathrm{G}::: \mathrm{G}^{\bullet+} \leftrightarrows \mathrm{GH}^{+}:: \mathrm{G}(\mathrm{N} 1-\mathrm{H})^{\bullet}\right]$ leads to the hydration of $\mathrm{G}^{\bullet+}$ within the millisecond time domain, and is followed by the formation of the 8-oxo-G lesions [78].

The first study on the UV-induced ionization of G-quadruplexes was reported by Markovitsi and co-workers [79]. Using nanosecond time-resolved spectroscopy corroborated by TD-DFT calculations and the telomeric sequence Tel21 (cf. Figure 12B) in buffered solutions containing $\mathrm{Na}^{+}$cations, they showed that irradiation at $266 \mathrm{~nm}$, corresponding to an energy significantly lower than the guanine ionization potential, provokes one-photon ionization in aqueous solution, affording the guanyl radical. The fate of guanine radicals is followed over five orders of magnitude of time: (i) up to $30 \mathrm{~ns} 100 \% \mathrm{G}^{\bullet+}$, (ii) in $3 \mu \mathrm{ss} 50 \%$ $\mathrm{G}^{\bullet+}$ and $50 \%$ anti-G(N2-H) ${ }^{\bullet}$ that become $35 \% \mathrm{G}^{\bullet+}$ and $50 \% \mathrm{G}(\mathrm{N} 2-\mathrm{H})^{\bullet}$ in $20 \mu \mathrm{s}$; (iii) in $5 \mathrm{~ms}$ $50 \% \mathrm{G}(\mathrm{N} 1-\mathrm{H})^{\bullet}$ that reaches $6 \%$ in $180 \mathrm{~ms}$. The two main features are a long-lived $\mathrm{G}^{\bullet+}$ with respect to ds-ODNs due to the secondary structure and the detection of the two guanyl radicals, including the tautomerization anti-G(N2-H) $\rightarrow \mathrm{G}(\mathrm{N} 1-\mathrm{H})^{\bullet}$, which takes place on 
the millisecond timescale. The calculations indicated that anti-G(N2-H) ${ }^{\bullet}$ is $12.1 \mathrm{~kJ} \mathrm{~mol}^{-1}$ more stable than the G(N1-H) ${ }^{\bullet}$ in the simulated environment of Tel21/ $\mathrm{Na}^{+}$[79]. Similar behaviors were also reported for Tel25/ $\mathrm{Na}^{+}[63]$ and TG4T/ $/ \mathrm{Na}^{+}[80]$, although their guanines adopt, respectively, antiparallel and parallel orientations in respect of the glycosidic bonds. By replacing $\mathrm{Na}^{+}$with $\mathrm{K}^{+}$in Tel21 [81] and TG4T [82], some important changes were observed: the quantum yield of one-photon ionization at $266 \mathrm{~nm}$ was twice as high in both systems and the anti-G(N2-H)${ }^{\bullet}$ radical decayed faster. Moreover, in the case of $\mathrm{TG} 4 \mathrm{~T} / \mathrm{K}^{+}$, the tautomerization step $\mathrm{G}(\mathrm{N} 2-\mathrm{H})^{\bullet} \rightarrow \mathrm{G}(\mathrm{N} 1-\mathrm{H})^{\bullet}$ is suppressed. Such a behavior shows that the nature of the metal ion plays an important role in the reaction mechanism.

It is also worth mentioning the formation of 8-oxo-G in the comparative study on Tel21/ $\mathrm{Na}^{+}$and TG4T/ $\mathrm{Na}^{+}$, where for the former, the yield of 8-oxo-G is much higher than that of the latter $[79,80]$. As the fate of $G^{\bullet+}$ is split between hydration vs. deprotonation, the authors suggested that the $G^{\bullet+}$ population survives on the millisecond timescale in Tel21/ $\mathrm{Na}^{+}$, whereas the deprotonation is much faster in TG4T/Na+ ${ }^{+}$, thus rendering the reaction path leading to 8-oxodG less probable. Markovitsi and co-workers recently summarized their work on the guanyl radicals in ds-ODNs and G-quadruplexes [64,83].

Two main questions remain open on the guanyl radical in G-quadruplexes: (i) what is the mechanism of tautomerization anti-G(N2-H) ${ }^{\bullet} \rightarrow \mathrm{G}(\mathrm{N} 1-\mathrm{H})^{\bullet}$, and (ii) based on the results described above, the major oxidative damage is expected to arise from deprotonated radicals; what are the end-products of the two guanyl radicals and their relation with the 8-oxo-G lesion. Theoretical calculations combined with time-resolved methodologies and product studies will certainly help understand such pending radical mechanisms.

\section{Reaction of Hydroxyl Radical with ODNs and DNA}

The reaction of $\mathrm{HO}^{\bullet}$ with $\mathrm{G}$ in the macromolecular environment is worth a special comment, because the behavior is quite different from the reaction of $\mathrm{HO}{ }^{\bullet}$ with simple Guo or dGuo (Section 5). The four common nucleosides of DNA (dGuo, dAdo, dCyt, and Thy) react with $\mathrm{HO}^{\bullet}$ at close to diffusion-controlled rates $\left(4-7 \times 10^{9} \mathrm{M}^{-1} \mathrm{~s}^{-1}\right)$, with the pyrimidine nucleosides being slightly higher [13]. The sites of DNA attack by diffusible $\mathrm{HO}^{\bullet}$ radicals are known to be either the hydrogen atom abstraction from the $2^{\prime}$-deoxyribose units or the addition to the base moieties, with the latter being the predominant one (accounting for $85-90 \%$ of attacked sites) [13].

The reaction of $\mathrm{HO}^{\bullet}$ with the 21-mer ds-ODNs reported in Figure 13A shows that increasing concentrations of oxygen lead to elevated levels of 8-oxo-G. The 8-oxo-G levels vary from 1.35 8-oxo-dG/10 $\mathrm{dG} / \mathrm{Gy}$ in the absence of $\mathrm{O}_{2}$ up to 4.60 for $2.01 \times 10^{-4} \mathrm{M}$ of $\mathrm{O}_{2}(15 \%)$ [84]. The mechanism of the formation of 8-oxo-G by the reaction of $\mathrm{HO}^{\bullet}$ with ct-DNA and ds-ODNs in the presence of oxygen has been investigated in detail [85-87]. It was demonstrated that three pathways contribute to the formation of 8-oxo-dG, as shown in Figure 14. The direct addition of $\mathrm{HO}^{\bullet}$ to the $\mathrm{C} 8$ position of the guanine moiety to form 8 -HO-G accounts for the minor path $(\sim 5 \%)$, whereas the remaining $\sim 95 \%$ of 8 -oxo-dG are produced by two types of reactions in approximately equal amounts involving DNA radicals, that is, one-electron oxidation (probably by a variety of reactions not very well understood) followed by hydration reaction $(\sim 4 \%)$ or an intramolecular addition of a transiently generated pyrimidine peroxyl radical onto the $\mathrm{C} 8$ of a vicinal guanine base $(\sim 50 \%)$. As mentioned earlier, the Fapy-G lesions are chemically related to 8 -oxo-G as they are generated from the same intermediate $8-\mathrm{HO}-\mathrm{dG}^{\bullet}$ (Figure 14). The formation of Fapy-G is dependent on the oxygen concentration and the redox environment. [52,53]. 
(A)

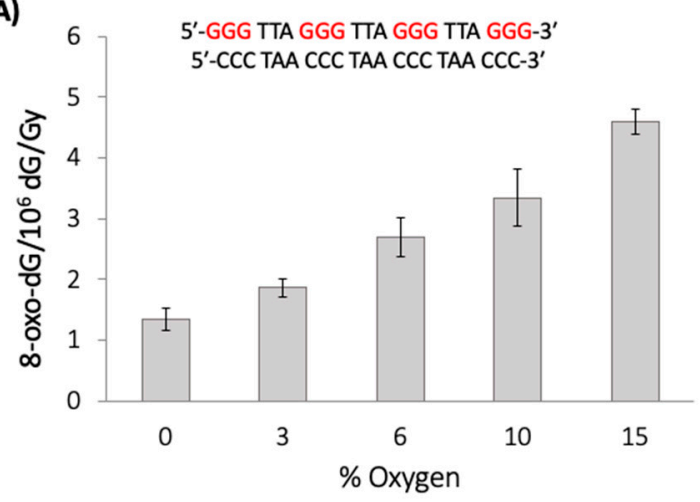

(B)

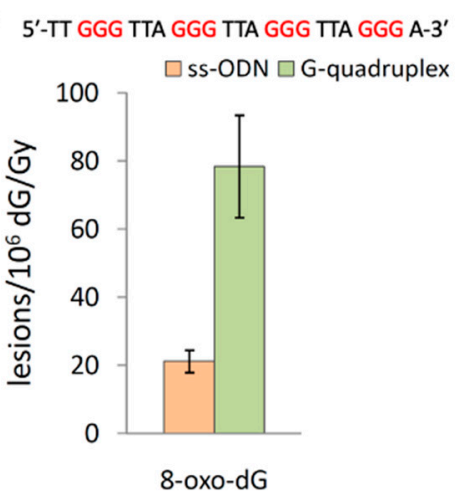

Figure 13. (A) Radiation-induced formation of 8-oxo-dG in ds-ODNs at increasing concentrations of oxygen; data from [84]. (B) Radiation-induced formation of 8-oxo-dG lesions in ss-ODN (nonfolded state) and G-quadruplex (folded state) in deareated conditions; the G-quadruplex was prepared by dissolving the oligonucleotides in $10 \mathrm{mM}$ of $\mathrm{KH}_{2} \mathrm{PO}_{4}$ buffer containing $70 \mathrm{mM}$ of $\mathrm{KClO}_{4}(\mathrm{pH} 7.0)$. Values represent the mean \pm SD per $10^{6} \mathrm{dG}$ per Gy of $\gamma$-irradiation in the range from 0 to $60 \mathrm{~Gy}$ of irradiation.

A pulse radiolysis study reported the reaction of four 12 mer ONDs with four or two Gs subjected, either as ss-ODNs or ds-ODNs, to the reaction with $\mathrm{HO}^{\bullet}$ radicals using an intensified charge-coupled device (ICCD) as an alternative to the photomultiplier tube (PMT) for transient spectra measurements [88]. The characteristic band $>600 \mathrm{~nm}$ of the guanyl radical $\mathrm{G}(\mathrm{N} 2-\mathrm{H})^{\bullet}$ was present in ss-ODNs and disappeared on the microsecond timescale, but it was absent in ds-ODNs.

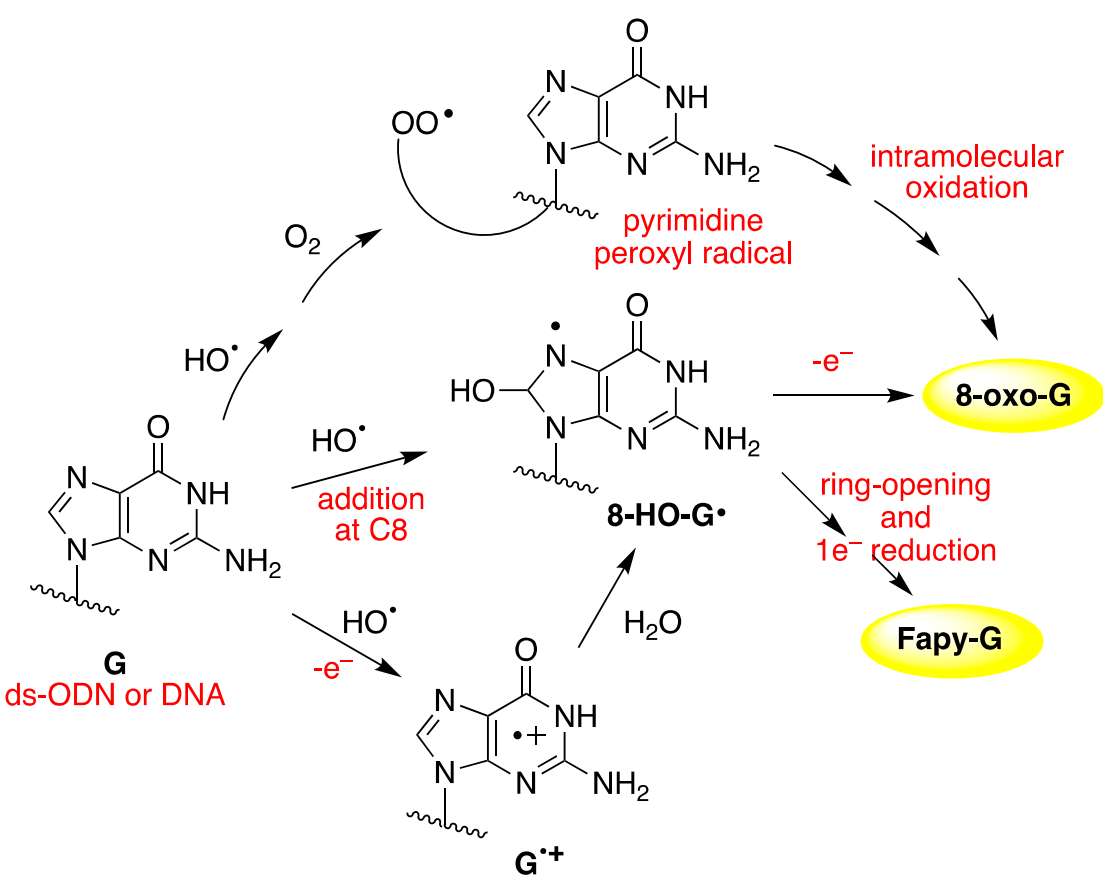

Figure 14. Reaction mechanism for the formation of 8-oxo-G in ds-ODN. For the hydration reaction of $\mathrm{G}^{\bullet+}$ and identification of $8-\mathrm{HO}-\mathrm{G}^{\bullet}$ by electron spin resonance (ESR) in DNA, see reference [89].

The impact of G-quadruplex folding with respect to unfolded sequences in ss-ODNs on the formation of 8-oxo-G lesions was also investigated [90]. In particular, the unfolded sequences of TG4T and mutated Tel24, as well as the G-quadruplexes of TG4T/K $\mathrm{K}^{+}$and $\mathrm{Te} 24 / \mathrm{K}^{+}$(see Figure 12B), were exposed to $\mathrm{HO}^{\bullet}$ radicals generated by $\gamma$-radiolysis, and the 8 -oxo-G was then quantified via stable isotope dilution LC-MS/MS analysis. Figure 13B shows the results of Tel24, where 8-oxo-G lesions formation in the folded G-quadruplex 
is $\sim 4$ folds higher than the unfolded sequences (78.4 vs. 21.2 of $8-o x o-G / 10^{6} \mathrm{dG} / \mathrm{Gy}$, respectively). In the TG4T system, the 8-oxo-G lesions formation in tetramolecular parallelstranded G-quadruplex is $\sim 2.8$ folds higher than the monomolecular sequences (39.9 vs. 14.4 of $8-o x o-G / 10^{6} \mathrm{dG} / \mathrm{Gy}$, respectively). Therefore, the self-organization of guanines in the G-quadruplex tetrads produced $\sim 3$ - and $\sim 4$-fold increases in 8-oxo-G yields, indicating that the G-quadruplex is significantly more susceptible to $\mathrm{HO}^{\bullet}$ oxidation. The mechanism of the formation of 8-oxo-G by $\mathrm{HO}^{\bullet}$ in G-quadruplexes is not clear at present, with the addition at the $\mathrm{C} 8$ position being the most reasonable key step.

\section{Biomarkers of Guanine DNA Damage}

Reactive oxygen and nitrogen species (ROS/RNS) are produced in a wide range of physiological processes and are also responsible for a variety of pathological processes [1-3]. Persistent oxidative stress developed at sites of chronic inflammation is characterized by overproduction of ROS/RNS, which targets cellular DNA, and, as a consequence, may lead to mutations and cancer. For example, the 8-oxo-G lesion is genotoxic [91], and failure to remove this lesion before replication induces the $\mathrm{G}:: \mathrm{C} \rightarrow \mathrm{T}:: \mathrm{A}$ transversion mutation.

The ROS/RNS network includes molecules such as hydrogen peroxide $\left(\mathrm{H}_{2} \mathrm{O}_{2}\right)$, hypochlorous acid $(\mathrm{HOCl})$, and peroxynitrite $\left(\mathrm{ONOO}^{-}\right)$, as well as radicals such as the superoxide radical anion $\left(\mathrm{O}_{2}{ }^{\bullet-}\right)$, nitric oxide $\left.(\mathrm{NO})^{\bullet}\right)$, hydroxyl radical $(\mathrm{HO})^{\bullet}$, nitrogen dioxide $\left(\mathrm{NO}_{2}{ }^{\bullet}\right)$, and carbonate radical anion $\left(\mathrm{CO}_{3}{ }^{--}\right)$. Most of these species can react with DNA, and the nucleobase guanine with the lowest reduction potential is the dominant site for oxidation within DNA through the hole transfer [4-10]. Analytical protocols and, in particular, liquid chromatography-tandem mass spectrometry (LC-MS/MS) allow the identification of the DNA lesions with high-accuracy in cellular DNA after enzymatic digestion, as reviewed recently $[92,93]$. The main guanine-derived lesions observed in vitro and/or in vivo from oxidatively generated DNA damage are collected in Figure 15 and divided in four groups, depending on the precursor. In model DNA studies, the relative yields of these lesions depend on the reaction context, and several comparative studies with various types of oxidants are reported [94].

8-Oxo-G and Fapy-G are chemically connected because they derive from the same radical precursor (8-hydroxyl radical adduct, $8-\mathrm{HO}-\mathrm{G}^{\bullet}$ ) and their comparisons have been extensively treated [52,92]. Fapy-G due to its instability is mainly detected as the free base modification (i.e., Fapy-Gua), and both GC-MS/MS and LC-MS/MS techniques with the isotope dilution approach have been used for the measurements in vitro and in vivo [95]. A large number of publications deal with these lesions not only in vitro but also in vivo [96,97]. There are a few studies at the macromolecular level in vitro for the formation of Ih, Iz, Z, Sp, and Gh lesions. The Sp and Gh lesions derive from further oxidation products of 8-oxo-G, whereas the $\mathrm{d} 2 \mathrm{Ih}, \mathrm{dIz}$, and $\mathrm{dZ}$ lesions are the final products of the further reaction of $\mathrm{G}^{\bullet+}$ or $\mathrm{G}(\mathrm{N} 1-\mathrm{H})^{\bullet}$ with oxyl radicals generated under aerobic conditions in vitro. Comparative analyses of the four oxidized $\mathrm{G}$ lesions (8-oxo-G, Z, Sp, and $\mathrm{Gh}$ ) from the reaction of ct-DNA with $\mathrm{HO}^{\bullet}, \mathrm{ONOO}^{-}$, and ${ }^{1} \mathrm{O}_{2}$ [98], as well as of four oxidized G lesions (8-oxo-G, $\mathrm{Z}$, and 8- $\mathrm{NO}_{2}-\mathrm{G}$ ) from the reaction of ds-ODNs with $\mathrm{HO}^{\bullet}$ and $\mathrm{NO}_{2} \cdot / \mathrm{CO}_{3}{ }^{\bullet-}$ [75], were examined using LC-MS/MS and isotopomeric internal standards. There are a few studies in murine models reporting the detection of dSp, dGh, and dZ [99].

$5^{\prime}, 8$-Cyclo-2'-deoxyguanosine ( $\mathrm{cdG}$ ) in its $5^{\prime} \mathrm{R}$ and $5^{\prime} \mathrm{S}$ diastereoisomeric forms results from the $\mathrm{C}^{\prime}$ radical cyclization on the $\mathrm{C} 8$ position of $\mathrm{G}$ (see Figure 5) [92,93]. Although the guanine DNA lesions mentioned above are generated by various ROS (including $\mathrm{HO}{ }^{\bullet}$ ), the formation of $5^{\prime} \mathrm{R}$-cdG and $5^{\prime} \mathrm{S}$-cdG lesions in vitro and in vivo relies exclusively on the $\mathrm{HO}^{\bullet}$ attack. Recent results on the quantification of $5^{\prime} \mathrm{R}-\mathrm{cdG}, 5^{\prime} \mathrm{S}-\mathrm{cdG}$, and 8-oxo-G lesions in various types of biological specimens associated with the cellular repair efficiency, as well as with distinct pathologies, have been reported, providing some insights on their biological significance [92]. 
Precursors

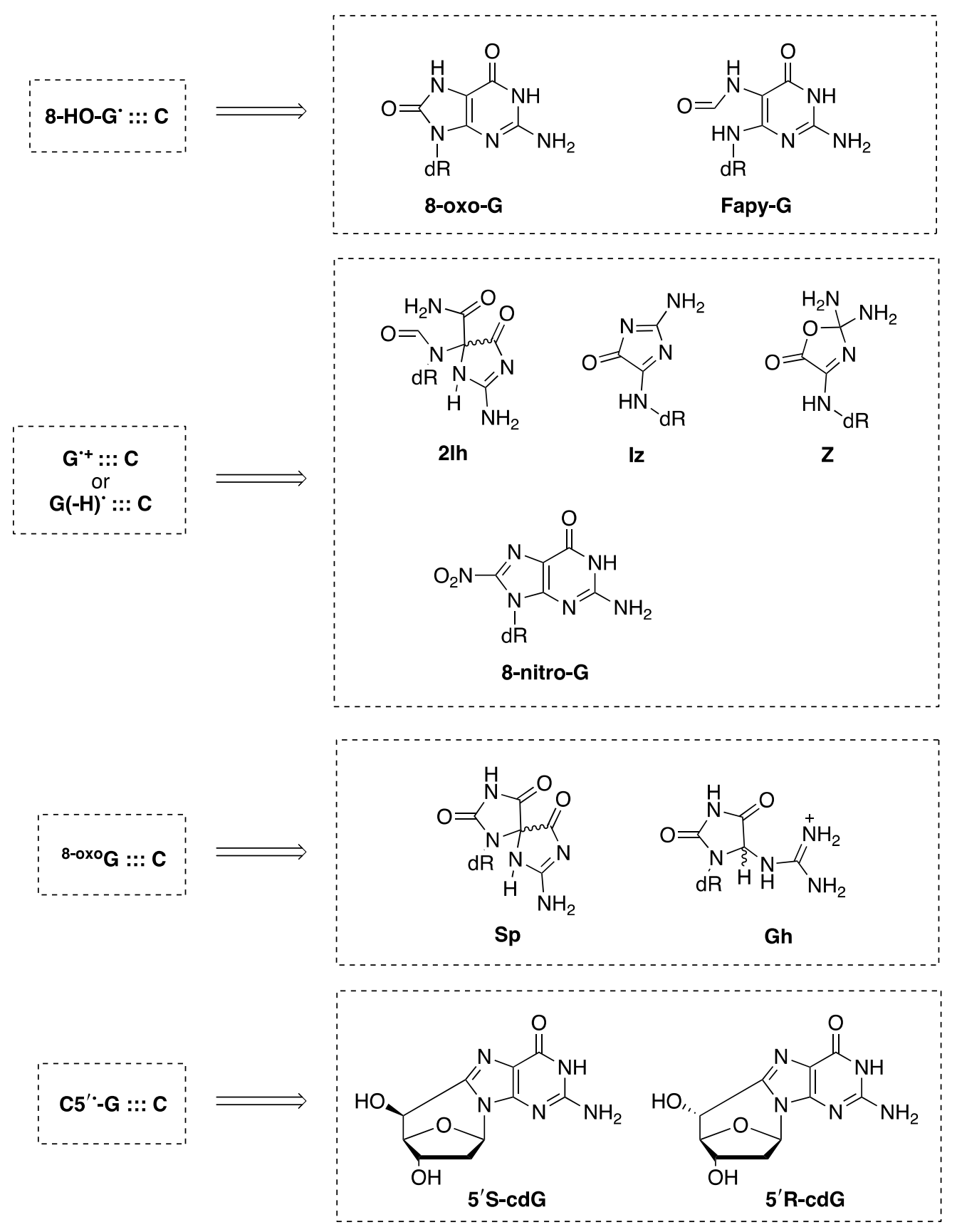

Figure 15. (Left) The precursor of the lesions in ds-ODNs or DNA. (Right) Guanine-derived lesions detected in in vitro experiments by the reaction of reactive oxygen species (ROS) with ds-ODNs or naked DNA. Most of these lesions have also been found after oxidatively induced DNA damage in vivo.

Base excision repair (BER) is the major enzymatic pathway involved in the processing of base damages such as 8-oxo-G and Fapy-G by creating an abasic site [100]. Nucleotide excision repair (NER) pathways are the major cellular pathway for the repair of bulky adducts and other helix-distorting lesions such as $5^{\prime} \mathrm{R}$-cdG and $5^{\prime} \mathrm{S}-\mathrm{cdG}$ lesions [93]. Evidence has also been provided that the removal of some oxidatively generated purine DNA lesions involves the overlap of both pathways [101,102]. 


\section{Conclusions}

The one-electron oxidation of the guanine moiety $\left(\mathrm{G}^{\bullet+}\right)$ is the most relevant process generating transient precursors involved in the oxidative damage of DNA with a variety of end-products, including the 8-oxo-dG lesion. There is a plethora of experimental and theoretical papers dealing with the well-understood long-range charge transport in DNA with the final destination of the $G$ sites. Upon formation of $G^{\bullet+}$, two main paths are recognized: (i) a nucleophilic attack, such as the hydration reaction with the formation of $8-\mathrm{HOG}^{\bullet}$, and (ii) the prototropic equilibrium $\left[\mathrm{G}^{\bullet+}:: \mathrm{C} \leftrightarrows \mathrm{G}(-\mathrm{H})^{\bullet}::: \mathrm{CH}^{+}\right]$. Both are at the crossroads of various pathways to the end-products. Furthermore, the one-electron oxidation of the G-quadruplex, with their planar array stabilized by metal cations, represent another context of $\mathrm{G}^{\bullet+}$ fate.

For such a complex chemistry, it is obvious that the single nucleosides such as Guo or dGuo and the free base Gua have been the prototypes for experiments and theoretical calculations. However, neither Gua represents dGuo nor dGuo represents ODNs in their various supramolecular arrangements, and the extrapolation of its free radical chemistry can generate confusion. For example, for the introduction of the $\mathrm{HO}^{\bullet}$ radical reactivity toward DNA, the main path reported is the addition at the $C 4$ position followed by dehydration. There is no evidence for the existence of such a reaction. Overall, the reaction of $\mathrm{HO}^{\bullet}$ with the guanine moiety is strictly dependent on the molecular context. The chemistry changes completely on going from the free base (Gua) to the nucleoside (dGuo) and from dGuo to DNA or the G-quadruplex, as we described herein. Several authors have often reported the calculations of $\mathrm{HO}^{\bullet}$ with Gua for introducing the DNA damage, and this caused confusion in such a multidisciplinary field.

The two faces of the $\mathrm{G}^{\bullet}$ radical have been reproduced by various methods and at different levels of complexity. The paradigm of one-electron-oxidized guanosines formation under the one-electron reduction of 8-bromo-guanosines has been the driving force to obtain the two faces of $\mathrm{G}^{\bullet}$, i.e., $\mathrm{G}(\mathrm{N} 2-\mathrm{H})^{\bullet}$ and $\mathrm{G}(\mathrm{N} 1-\mathrm{H})^{\bullet}$, and their connection via tautomerization. This allowed the revision of the reaction of the $\mathrm{HO}^{\bullet}$ radical with guanosine derivatives, where the main path is the $\mathrm{H}$-atom abstraction from the exocyclic $\mathrm{NH}_{2}$ group. Both faces of the $\mathrm{G}^{\bullet}$ radical have been invoked in order to interpret the time-resolved spectroscopies at ds-ODNs, DNA, or G-quadruplexes ODNs and to associate them to 8 -oxo-G yields. This review presents a reasonable overview of the $\mathrm{G}^{\bullet}$ structure depending on molecular context and behavior.

The end-products (or lesions) of guanine DNA have been identified and successfully connected to the various mechanistic steps. Now, the comparative quantification of various purine lesions appears periodically and are related to health conditions. For example, 8-oxo-G and, to minor extent, Fapy-G have been measured in various human specimens and rationalized with various pathologies. Analogous data for the other lesions in Figure 15 are limited or absent. In the last two years, our group has been very active in the detection of $5^{\prime}, 8$-cyclopurine lesions (including the $5^{\prime} \mathrm{S}-\mathrm{cdG}$ and $5^{\prime} \mathrm{R}$-cdG reported in Figure 15), providing results from cells, animals, and humans. Further perspectives of transdisciplinary research combining chemistry, mechanisms, and lesions formation can be foreseen in order to reach a satisfactory comprehension of the guanine radical involvement in DNA damage and human health.

Funding: This research received no external funding.

Institutional Review Board Statement: Not applicable.

Informed Consent Statement: Not applicable.

Data Availability Statement: Not applicable.

Acknowledgments: I would like to thank Krzysztof Bobrowski, Carla Ferreri, Maurizio Guerra and Dimitra Markovitsi for helpful discussions.

Conflicts of Interest: The author declares no conflict of interest. 


\section{Appendix A}

In this section, some fundamental information regarding the methods of generation of the reactive species reported in this review by ionizing radiation are given in order to facilitate the nonexpert readers. The reader is referred to the literature for further information [103,104].

Radiolysis of neutral water leads to the species $\mathrm{e}_{\mathrm{aq}}{ }^{-}, \mathrm{HO}^{\bullet}$, and $\mathrm{H}^{\bullet}$, as shown in Reaction 1, where the values in parentheses represent the radiation chemical yields $(G)$ in units of $\mu \mathrm{mol} \mathrm{J}^{-1}$.

$$
\mathrm{H}_{2} \mathrm{O}+\gamma \text {-irr } \rightarrow \mathrm{e}_{\mathrm{aq}}{ }^{-}(0.27), \mathrm{HO}^{\bullet}(0.28), \mathrm{H}^{\bullet}(0.062)
$$

The reactions of $\mathrm{HO}^{\bullet}$ with the substrates were studied by irradiating $\mathrm{N}_{2} \mathrm{O}$-saturated solution $\left(\sim 0.02 \mathrm{M}\right.$ of $\left.\mathrm{N}_{2} \mathrm{O}\right)$; under these conditions, $\mathrm{e}_{\mathrm{aq}}{ }^{-}$are converted into the $\mathrm{HO}{ }^{\bullet}$ radical via Reaction $2\left(k_{2}=9.1 \times 10^{9} \mathrm{M}^{-1} \mathrm{~s}^{-1}\right)$, with $G\left(\mathrm{HO}^{\bullet}\right)=0.55 \mu \mathrm{mol} \mathrm{J}^{-1}$; i.e., $\mathrm{HO}^{\bullet}$ radicals and $\mathrm{H}^{\bullet}$ atoms account for 90 and $10 \%$, respectively, of the reactive species.

$$
\mathrm{e}_{\mathrm{aq}}{ }^{-}+\mathrm{N}_{2} \mathrm{O}+\mathrm{H}_{2} \mathrm{O} \rightarrow \mathrm{HO}^{-}+\mathrm{N}_{2}+\mathrm{HO}^{\bullet}
$$

The reactions of $\mathrm{e}_{\mathrm{aq}}{ }^{-}$with the substrates were studied by irradiating deoxygenated solutions containing $0.25 \mathrm{M}$ of $t-\mathrm{BuOH}$. In the presence of $t-\mathrm{BuOH}, \mathrm{HO}$ radicals are scavenged (Reaction $3, k_{3}=6.0 \times 10^{8} \mathrm{M}^{-1} \mathrm{~s}^{-1}$ ), whereas $\mathrm{H}^{\bullet}$ may be trapped only partially (Reaction $4, k_{4}=1.1 \times 10^{6} \mathrm{M}^{-1} \mathrm{~s}^{-1}$ ).

$$
\begin{gathered}
\mathrm{HO}^{\bullet}+\mathrm{t}-\mathrm{BuOH} \rightarrow\left(\mathrm{CH}_{3}\right)_{2} \mathrm{C}(\mathrm{OH}) \mathrm{CH}_{2}{ }^{\bullet}+\mathrm{H}_{2} \mathrm{O} \\
\mathrm{H}^{\bullet}+\mathrm{t}-\mathrm{BuOH} \rightarrow\left(\mathrm{CH}_{3}\right)_{2} \mathrm{C}(\mathrm{OH}) \mathrm{CH}_{2} \bullet+\mathrm{H}_{2}
\end{gathered}
$$

The sulfate radical anion, $\mathrm{SO}_{4}{ }^{\bullet-}$, was generated by irradiating Ar-purged solutions containing $10 \mathrm{mM}$ of peroxydisulfate $\mathrm{S}_{2} \mathrm{O}_{8}{ }^{2-}$ and $\sim 0.1 \mathrm{M}$ of $t-\mathrm{BuOH}$ as a $\mathrm{HO}^{\bullet}$ radical scavenger (Reaction 5, $k_{5}=1.2 \times 10^{10} \mathrm{M}^{-1} \mathrm{~s}^{-1}$ ).

$$
\mathrm{e}_{\mathrm{aq}}{ }^{-}+\mathrm{S}_{2} \mathrm{O}_{8}{ }^{2-} \rightarrow \mathrm{SO}_{4}{ }^{2-}+\mathrm{SO}_{4}{ }^{\bullet-}
$$

The dibromine radical anion, $\mathrm{Br}_{2}{ }^{\bullet-}$, was generated by irradiating $\mathrm{N}_{2} \mathrm{O}$-saturated solutions containing $0.1 \mathrm{M}$ of $\mathrm{KBr}$. Under these conditions, at $\mathrm{pH} 7$, the $\mathrm{HO}^{\bullet}$ radical is converted into $\mathrm{Br}_{2}{ }^{--}$, through the process shown in Reaction $6\left(k_{6}=1.1 \times 10^{10} \mathrm{M}^{-1} \mathrm{~s}^{-1}\right)$.

$$
\mathrm{HO}^{\bullet}+2 \mathrm{Br}^{-} \rightarrow \mathrm{Br}_{2}^{\bullet-}+\mathrm{HO}^{-}
$$

\section{References}

1. Dizdaroglu, M.; Lloyd, R.S. DNA Damage, DNA Repair and Disease; Royal Society of Chemistry: Croydon, UK, 2021.

2. Markkanen, E. Not breathing is not an option: How to deal with oxidative DNA damage. DNA Repair 2017, 59, 82-105. [CrossRef] [PubMed]

3. Tubbs, A.; Nussenzweig, A. Endogenous DNA damage as a source of genomic instability in cancer. Cell 2017, 168, 644-656. [CrossRef] [PubMed]

4. Genereux, J.C.; Barton, J.K. Mechanisms for DNA Charge Transport. Chem. Rev. 2010, 110, 1642-1662. [CrossRef] [PubMed]

5. Sontz, P.A.; Muren, N.B.; Barton, J.K. DNA Charge Transport for Sensing and Signaling. Acc. Chem. Res. 2012, 45, 1792-1800. [CrossRef]

6. Zwang, T.J.; Tse, E.C.M.; Barton, J.K. Sensing DNA through DNA Charge Transport. ACS Chem. Biol. 2018, 13, 1799-1809. [CrossRef]

7. Kawai, K.; Majima, T. Hole Transfer Kinetics of DNA. Acc. Chem. Res. 2013, 46, 2616-2625. [CrossRef]

8. Fujitsuka, M.; Majima, T. Charge Transfer Dynamics in DNA Revealed by Time-Resolved Spectroscopy. Chem. Sci. 2017, 8, 1752-1762. [CrossRef]

9. Lewis, F.D.; Young, R.M.; Wasielewski, M.R. Tracking Photoinduced Charge Separation in DNA: From Start to Finish. Acc. Chem. Res. 2018, 51, 1746-1754. [CrossRef]

10. Peluso, A.; Caruso, T.; Landi, A.; Capobianco, A. The Dynamics of Hole Transfer in DNA. Molecules 2019, 24, 4044. [CrossRef] 
11. Chatgilialoglu, C.; Caminal, C.; Altieri, A.; Vougioukalakis, G.C.; Mulazzani, Q.G.; Gimisis, T.; Guerra, M. Tautomerism in the guanyl radicals. J. Am. Chem. Soc. 2006, 128, 13796-13805. [CrossRef]

12. Steenken, S. Purine bases, nucleosides, and nucleotides: Aqueous solution redox chemistry and transformation reactions of their radical cations and $\mathrm{e}^{-}$and $\mathrm{OH}$ adducts. Chem. Rev. 1989, 89, 503-520. [CrossRef]

13. Von Sonntag, C. Free-Radical-Induced DNA Damage and Its Repair, A Chemical Perspective; Springer: Berlin, Germany, 2006.

14. Candeias, L.P.; Steenken, S. Structure and acid-base properties of one-electron-oxidized deoxyguanosine, guanosine, and 1-methylguanosine. J. Am. Chem. Soc. 1989, 111, 1094-1099. [CrossRef]

15. Steenken, S.; Jovanovic, S.V. How easily oxidizable Is DNA? One-electron reduction potentials of adenosine and guanosine radicals in aqueous solution. J. Am. Chem. Soc. 1997, 119, 617-618. [CrossRef]

16. Kobayashi, K.; Tagawa, S. Direct Observation of Guanine Radical Cation Deprotonation in Duplex DNA Using Pulse Radiolysis. J. Am. Chem. Soc. 2003, 125, 10213-10218. [CrossRef]

17. Zhang, X.; Jie, J.; Song, D.; Su, H. Deprotonation of Guanine Radical Cation G ${ }^{\bullet+}$ Mediated by the Protonated Water Cluster. J. Phys. Chem. A 2020, 124, 6076-6083. [CrossRef]

18. Latus, A.; Alam, M.S.; Mostafavi, M.; Marignier, J.-L.; Maisonhaute, E. Guanosine radical reactivity explored by pulse radiolysis coupled with transient electrochemistry. Chem. Commun. 2015, 51, 9089-9092. [CrossRef]

19. Adhikary, A.; Kumar, A.; Becker, D.; Sevilla, M.D. The Guanine Cation Radical: Investigation of Deprotonation States by ESR and DFT. J. Phys. Chem. B 2006, 110, 24171-24180. [CrossRef]

20. Hole, E.O.; Sagstuen, E.; Nelson, W.H.; Close, D.M. The Structure of the guanine cation: ESR/ENDOR of cyclic guanosine monophosphate single crystals after $X$ irradiation at $10 \mathrm{~K}$. Radiat. Res. 1992, 129, 1-10. [CrossRef]

21. Choi, J.; Yang, C.; Fujitsuka, M.; Tojo, S.; Ihee, H.; Majima, T. Proton Transfer of Guanine Radical Cations Studied by Time-Resolved Resonance Raman Spectroscopy Combined with Pulse Radiolysis. J. Phys. Chem. Lett. 2015, 6, 5045-5050. [CrossRef]

22. Saprygina, N.N.; Morozova, O.B.; Abramova, T.V.; Grampp, G.; Yurkovskaya, A.V. Oxidation of Purine Nucleotides by Triplet 3,3' 4, 4' ${ }^{\prime}$-Benzophenone Tetracarboxylic Acid in Aqueous Solution: pH-Dependence. J. Phys. Chem. A 2014, 118, 4966-4974. [CrossRef]

23. Morozova, O.B.; Fishman, N.N.; Yurkovskaya, A.V. Indirect NMR detection of transient guanosyl radical protonation in neutral aqueous solution. Phys. Chem. Chem. Phys. 2017, 19, 21262-21266. [CrossRef]

24. Morozova, O.B.; Fishman, N.N.; Yurkovskaya, A.V. Kinetics of Reversible Protonation of Transient Neutral Guanine Radical in Neutral Aqueous Solution. ChemPhysChem 2018, 19, 2696-2702. [CrossRef]

25. Sevilla, M.D.; Kumar, A.; Adhikary, A. Comment on Proton Transfer of Guanine Radical Cations Studied by Time-Resolved Resonance Raman Spectroscopy Combined with Pulse Radiolysis. J. Phys. Chem. B 2016, 120, 2984-2986. [CrossRef]

26. Knobloch, B.; Sigel, H.; Okruszek, A.; Sigel, R.K.O. Acid-base properties of the nucleic-acid model 2'-deoxyguanylyl(5' $\left.\rightarrow 3^{\prime}\right)-2^{\prime}-$ deoxy-5'-guanylate, $\mathrm{d}(\mathrm{pGpG})^{3-}$, and of related guanine derivatives. Org. Biomolec. Chem. 2006, 4, 1085-1090. [CrossRef]

27. Chatgilialoglu, C.; D'Angelantonio, M.; Guerra, M.; Kaloudis, P.; Mulazzani, Q.G. A reevaluation of the ambident reactivity of guanine moiety towards hydroxyl radicals. Angew. Chem. Int. Ed. 2009, 48, 2214-2217. [CrossRef]

28. Chatgilialoglu, C.; Caminal, C.; Guerra, M.; Mulazzani, Q.G. Tautomers of one-electron oxidized guanosine. Angew. Chem. Int. Ed. 2005, 44, 6030-6032. [CrossRef]

29. Ioele, M.; Bazzanini, R.; Chatgilialoglu, C.; Mulazzani, Q.G. Chemical radiation studies of 8-bromoguanosine in aqueous solutions. J. Am. Chem. Soc. 2000, 122, 1900-1907. [CrossRef]

30. Adhikary, A.; Kumar, A.; Munafo, S.A.; Khanduri, D.; Sevilla, M.D. Prototropic equilibria in DNA containing one-electron oxidized GC:intra-duplex vs. duplex to solvent deprotonation. Phys. Chem. Chem. Phys. 2010, 12, 5353-5368. [CrossRef]

31. Martínez-Fernández, L.; Cerezo, J.; Asha, H.; Santoro, F.; Coriani, S.; Improta, R. The absorption apectrum of guanine based radicals: A comparative computational analysis. ChemPhotoChem 2019, 3, 846-855. [CrossRef]

32. Candeias, L.P.; Steenken, S. Reaction of $\mathrm{HO}^{\bullet}$ with guanine derivatives in aqueous solution: Formation of two different redoxactive $\mathrm{OH}$-adduct radicals and their unimolecular transformation reactions. Properties of G(-H). Chem. Eur. J. 2000, 6, 475-484. [CrossRef]

33. Chatgilialoglu, C.; D'Angelantonio, M.; Kciuk, G.; Bobrowski, K. New insights into the reaction paths of hydroxyl radicals with 2'-deoxyguanosine. Chem. Res. Toxicol. 2011, 24, 2200-2206. [CrossRef] [PubMed]

34. D'Angelantonio, M.; Russo, M.; Kaloudis, P.; Mulazzani, Q.G.; Wardman, P.; Guerra, M.; Chatgilialoglu, C. Reaction of hydrated electrons with guanine derivatives: Tautomerism of intermediate species. J. Phys. Chem. B 2009, 113, 2170-2176. [CrossRef] [PubMed]

35. Chatgilialoglu, C.; Bazzanini, R.; Jimenez, L.B.; Miranda, M.A. (5'S)- and (5'R)-5',8-cyclo-2'-deoxyguanosine: Mechanistic insights on the 2'-deoxyguanosin-5'-yl radical cyclization. Chem. Res. Toxicol. 2007, 20, 1820-1824. [CrossRef] [PubMed]

36. Phadatare, S.D.; Sharma, K.K.K.; Rao, B.S.M.; Naumov, S.; Sharma, G.K. Spectra Characterization of Guanine C4-OH Adduct: A Radiation and Quantum Chemical Study. J. Phys. Chem. B 2011, 115, 13650-13658. [CrossRef] [PubMed]

37. Liska, A.; Triskova, I.; Ludvik, J.; Trnkova, L. Oxidation potentials of guanine, guanosine and guanosine-5'-monophosphate: Theory and experiment. Electrochim. Acta 2019, 318, 108-119. [CrossRef]

38. Kumar, A.; Pottiboyina, V.; Sevilla, M.D. Hydroxyl Radical (OH·) Reaction with Guanine in an Aqueous Environment: A DFT Study. J. Phys. Chem. B 2011, 115, 15129-15137. [CrossRef] [PubMed]

39. Dizdaroglu, M.; Jaruga, P. Mechanism of free radical-induced damage to DNA. Free Radic. Res. 2012, 46, 382-419. [CrossRef] 
40. Dizdaroglu, M. Oxidatively induced DNA damage: Mechanisms, repair and disease. Cancer Lett. 2012, 327, 26-47. [CrossRef]

41. Kaloudis, P.; Paris, C.; Vrantza, D.; Encinas, S.; Perez-Ruiz, R.; Miranda, M.A.; Gimisis, T. Photolabile N-hydroxypyrid-2(1H)-one derivatives of guanine nucleosides: A new method for independent guanine radical generation. Org. Biomol. Chem. 2009, 7, 4965-4972. [CrossRef]

42. Zheng, L.; Greenberg, M.M. Independent generation and reactivity of 2'-deoxyguanosin-N1-yl radical. J. Org. Chem. 2020, 85, 8665-8672. [CrossRef]

43. Zheng, 1.; Xiaojuan Dai, X.; Su, H.; Greenberg, M.M. Independent generation and time-resolved detection of 2'-deoxyguanosinN2-yl Radicals. Angew. Chem. Int. Ed. 2020, 59, 13406-13413. [CrossRef]

44. Marcus, Y.; Migron, Y. Polarity, Hydrogen Bonding, and Structure of Mixtures of Water and Cyanomethane. J. Phys. Chem. 1991, 95, 400-406. [CrossRef]

45. Mountain, R.D. Microstructure and Hydrogen Bonding in Water-Acetonitrile Mixtures. J. Phys. Chem. B 2010, 114, 16460-16464. [CrossRef]

46. Lewandowska-Andralojc, A.; Hug, G.L.; Marciniak, B.; Hörner, G.; Swiatla-Wojcik, D. Water-triggered photoinduced electron transfer in acetonitrile-Water binary solvent. Solvent microstructure-tuned reactivity of hydrophobic solutes. J. Phys. Chem. B 2020, 124, 5654-5664.

47. Pacher, P.; Beckman, J.S.; Liaudet, L. Nitric oxide and peroxynitrite in health and disease. Physiol. Rev. 2007, 87, 315-424. [CrossRef]

48. Illes, E.; Patra, S.G.; Marks, V.; Mizrahi, A.; Meyerstein, D. The Fe ${ }^{\mathrm{II}}$ (citrate) Fenton reaction under physiological conditions. J. Inorg. Biochem. 2020, 206, 111018. [CrossRef]

49. Shafirovich, V.; Dourandin, A.; Huang, W.; Geacintov, N.E. The carbonate radical is a site-selective oxidizing agent of guanine in double-stranded oligonucleotides. J. Biol. Chem. 2001, 276, 24621-24626. [CrossRef]

50. Wang, Y.; An, P.; Li, S.; Zhou, L. The oxidation mechanism and kinetics of 2 '-deoxyguanosine by carbonate radical anion. Chem. Phys. Lett. 2020, 739, 136982. [CrossRef]

51. Fleming, A.M.; Burrows, C.J. Iron Fenton oxidation of $2^{\prime}$-deoxyguanosine in physiological bicarbonate buffer yields products consistent with the reactive oxygen species carbonate radical anion not hydroxyl radical. Chem. Commun. 2020, 56, 9779-9782. [CrossRef]

52. Dizdaroglu, M.; Kirkali, G.; Jaruga, P. Formamidopyrimidines in DNA: Mechanisms of formation, repair, and biological effects. Free Radic. Biol Med. 2008, 45, 1610-1621. [CrossRef]

53. Greenberg, M.M. The formamidopyrimidines: Purine lesions formed in competition with 8-oxopurines from oxidative stress. Acc. Chem. Res. 2012, 45, 588-597. [CrossRef] [PubMed]

54. Steenken, S.; Jovanovic, S.V.; Bietti, M.; Bernhard, K. The trap depth (in DNA) of 8-oxo-7,8-dihydro-2'deoxyguanosine as derived from electron-transfer equilibria in aqueous solution. J. Am. Chem. Soc. 2000, 122, 2373-2374. [CrossRef]

55. Fleming, A.M.; Muller, J.G.; Dlouhy, A.C.; Burrows, C.J. Structural context effects in the oxidation of 8-oxo-7,8-dihydro-2'deoxyguanosine to hydantoin products: Electrostatics, base stacking, and base pairing. J. Am. Chem. Soc. 2012, 134, 15091-15102. [CrossRef] [PubMed]

56. Fleming, A.M.; Muller, J.G.; Ji, I.; Burrows, C.J. Characterization of 2'-deoxyguanosine oxidation products observed in the Fentonlike system $\mathrm{Cu}(\mathrm{II}) / \mathrm{H} 2 \mathrm{O} 2$ /reductant in nucleoside and oligodeoxynucleotide contexts. Org. Biomol. Chem. 2011, 9, 3338-3348. [CrossRef]

57. Alshykhly, O.R.; Fleming, A.M.; Burrows, C.J. 5-Carboxamido-5-formamido-2-iminohydantoin, in Addition to 8-oxo-7,8Dihydroguanine, Is the Major Product of the Iron-Fenton or X-ray Radiation-Induced Oxidation of Guanine under Aerobic Reducing Conditions in Nucleoside and DNA Contexts. J. Org. Chem. 2015, 80, 6996-7007. [CrossRef]

58. Rokhlenko, Y.; Geacintov, N.E.; Shafirovich, V. Lifetimes and reaction pathways of guanine radical cations and neutral guanine radicals in an oligonucleotide in aqueous solutions. J. Am. Chem. Soc. 2012, 134, 4955-4962. [CrossRef]

59. Adhikary, A.; Khanduri, D.; Sevilla, M.D. Direct observation of the hole protonation state and hole localization site in DNAoligomers. J. Am. Chem. Soc. 2009, 131, 8614-8619. [CrossRef]

60. Kobayashi, K.; Yamagami, R.; Tagawa, S. Effect of base sequence and deprotonation of guanine cation radical in DNA. J. Phys. Chem. B 2008, 112, 10752-10757. [CrossRef]

61. Rokhlenko, Y.; Cadet, J.; Geacintov, N.E.; Shafirovich, V. Mechanistic aspects of hydration of guanine radical cations in DNA. J. Am. Chem. Soc. 2014, 136, 5956-5962. [CrossRef]

62. Banyasz, A.; Martínez-Fernández, L.; Improta, R.; Ketola, T.-M.; Balty, C.; Markovitsi, D. Radicals generated in alternating guanine cytosine duplexes by direct absorption of low-energy UV radiation. Phys. Chem. Chem. Phys. 2018, 20, 21381-21389. [CrossRef]

63. Balanikas, E.; Banyasz, A.; Baldacchino, G.; Markovitsi, D. Populations and Dynamics of Guanine Radicals in DNA strandsDirect versus Indirect Generation. Molecules 2019, 24, 2347. [CrossRef]

64. Balanikas, E.; Banyasz, A.; Douki, T.; Baldacchino, G.; Markovitsi, D. Guanine Radicals Induced in DNA by Low-Energy Photoionization. Acc. Chem. Res. 2020, 53, 1511-1519. [CrossRef]

65. Anderson, R.F.; Shinde, S.S.; Maroz, A. Cytosine-Gated Hole Creation and Transfer in DNA in Aqueous Solution. J. Am. Chem. Soc. 2006, 128, 15966-15967. [CrossRef] 
66. Shinde, S.S.; Maroz, A.; Hay, M.P.; Anderson, R.F. One-Electron Reduction Potential of the Neutral Guanyl Radical in the GC Base Pair of Duplex DNA. J. Am. Chem. Soc. 2009, 131, 5203-5207. [CrossRef]

67. Anderson, R.F.; Shinde, S.S.; Maroz, A.; Reynisson, J. The reduction potential of the slipped GC base pair in one-electron oxidized duplex DNA. Phys. Chem. Chem. Phys. 2020, 22, 642-646. [CrossRef]

68. Jaeger, W.M.; Schaefer, H.F., III. Characterizing Radiation-Induced Oxidation of DNA by Way of the Monohydrated GanineCytosine Radical Cation. J. Phys. Chem. B 2009, 113, 8142-8148. [CrossRef]

69. Kumar, A.; Sevilla, M.D. Influence of Hydration on Proton Transfer in the Guanine-Cytosine Radical Cation $\left(\mathrm{G}^{\bullet+}-\mathrm{C}\right)$ Base Pair: A Density Functional Theory Study. J. Phys. Chem. B 2009, 113, 11359-11361. [CrossRef]

70. Steenken, S.; Reynisson, J. DFT calculations on the deprotonation site of the one-electron oxidised guanine-cytosine base pair. Phys. Chem. Chem. Phys. 2010, 12, 9088-9093. [CrossRef]

71. Kumar, A.; Sevilla, M.D. Excited States of One-Electron Oxidized Guanine-Cytosine Base Pair Radicals: A Time Dependent Density Functional Theory Study. J. Phys. Chem. A 2019, 123, 3098-3108. [CrossRef]

72. Misiaszek, R.; Crean, C.; Joffe, A.; Geacintov, N.E.; Shafirovich, V. Oxidative DNA damage associated with combination of guanine and superoxide radicals and repair mechanisms via radical trapping. J. Biol. Chem. 2004, 279, 32106-32115. [CrossRef]

73. Misiaszek, R.; Crean, C.; Geacintov, N.E.; Shafirovich, V. Combination of Nitrogen Dioxide Radicals with 8-Oxo-7,8dihydroguanine and Guanine Radicals in DNA: Oxidation and Nitration End-Products. J. Am. Chem. Soc. 2005, 127, 2191-2200. [CrossRef]

74. Joffe, A.; Mock, S.; Yun, B.H.; Kolbanovskiy, A.; Geacintov, N.E.; Shafirovich, V. Oxidative Generation of Guanine Radicals by Carbonate Radicals and Their Reactions with Nitrogen Dioxide to Form Site Specific 5-Guanidino-4-nitroimidazole Lesions in Oligodeoxynucleotides. Chem. Res. Toxicol. 2003, 16, 966-973. [CrossRef]

75. Matter, B.; Seiler, C.L.; Murphy, K.; Ming, X.; Zhao, J.; Lindgren, B.; Jones, R.; Tretyakova, N. Mapping three guanine oxidation products along DNA following exposure to three types of reactive oxygen species. Free Radic. Biol. Med. 2018, 121, 180-189. [CrossRef]

76. Davis, J.T. G-Quartets 40 Years Later: From 5'-GMP to Molecular Biology and Supramolecular Chemistry. Angew. Chem. Int. Ed. 2004, 43, 668-698. [CrossRef]

77. Wu, L.D.; Liu, K.H.; Jie, J.L.; Song, D.; Su, H.M. Direct Observation of Guanine Radical Cation Deprotonation in G-Quadruplex DNA. J. Am. Chem. Soc. 2015, 137, 259-266. [CrossRef] [PubMed]

78. Merta, T.J.; Geacintov, N.E.; Shafirovich, V. Generation of 8-oxo-7,8-dihydroguanine in G-quadruplexes models of human telomere sequences by one-electron oxidation. Photochem. Photobiol. 2019, 95, 244-251. [CrossRef]

79. Banyasz, A.; Martinez-Fernandez, L.; Balty, C.; Perron, M.; Douki, T.; Improta, R.; Markovitsi, D. Absorption of Low-Energy UV Radiation by Human Telomere G-Quadruplexes Generates Long-Lived Guanine Radical Cations. J. Am. Chem. Soc. 2017, 139, 10561-10568. [CrossRef]

80. Banyasz, A.; Balanikas, E.; Martinez-Fernandez, L.; Baldacchino, G.; Douki, T.; Improta, R.; Markovitsi, D. Radicals generated in tetramolecular guanine quadruplexes by photo-ionization: Spectral and dynamical features. J. Phys. Chem. B 2019, 123, 4950-4957. [CrossRef]

81. Balanikas, E.; Banyasz, A.; Baldacchino, G.; Markovitsi, D. Guanine Radicals Generated in Telomeric G-quadruplexes by Direct Absorption of Low-Energy UV Photons: Effect of Potassium Ions. Molecules 2020, 25, 2094. [CrossRef]

82. Behmand, B.; Balanikas, E.; Martinez-Fernandez, L.; Improta, R.; Banyasz, A.; Baldacchino, G.; Markovitsi, D. Potassium Ions Enhance Guanine Radical Generation upon Absorption of Low-Energy Photons by G-quadruplexes and Modify Their Reactivity. J. Phys. Chem. Lett. 2020, 11, 1305-1309. [CrossRef]

83. Gustavsson, T.; Markovitsi, D. Fundamentals of the Intrinsic DNA Fluorescence. Acc. Chem. Res. 2021, 54, 1226-1235. [CrossRef] [PubMed]

84. Chatgilialoglu, C.; Eriksson, L.A.; Krokidis, M.G.; Masi, A.; Wang, S.-D.; Zhang, R. Oxygen dependent purine lesions in doublestranded oligodeoxynucleotides: Kinetic and computational studies highlight the mechanism for $5^{\prime}, 8$-cyplopurine formation. J. Am. Chem. Soc. 2020, 142, 5825-5833. [CrossRef] [PubMed]

85. Bergeron, F.; Auvre, F.; Radicella, J.P.; Ravanat, J.-L. HO ${ }^{\bullet}$ radicals induce an unexpected high proportion of tandem base lesions refractory to repair by DNA glycosylases. Proc. Natl. Acad. Sci. USA 2010, 107, 5528-5533. [CrossRef] [PubMed]

86. Ravanat, J.-L.; Breton, J.; Douki, T.; Gasparutto, D.; Grand, A.; Rachidi, W.; Sauvaigo, S. Radiation-mediated formation of complex damage to DNA: A chemical aspect overview. Br. J. Radiol. 2014, 87, 20130715. [CrossRef]

87. Robert, G.; Wagner, J.R. Tandem lesions arising from 5-(uracilyl)methyl peroxyl radical addition to guanine: Product analysis and mechanistic studies. Chem. Res. Toxicol. 2020, 33, 565-575. [CrossRef]

88. Chatgilialoglu, C.; Krokidis, M.G.; Masi, A.; Barata-Vallejo, S.; Ferreri, C.; Terzidis, M.A.; Szreder, T.; Bobrowski, K. New insights into the reaction paths of hydroxyl radicals with purine moieties in DNA and double-stranded oligonucleotides. Molecules 2019, 24, 3860. [CrossRef]

89. Shukla, L.I.; Adhikary, A.; Pazdro, R.; Becker, D.; Sevilla, M.D. Formation of 8-oxo-7,8-dihydroguanine-radicals in $\gamma$-irradiated DNA by multiple one-electron oxidations. Nucleic Acids Res. 2004, 32, 6565-6574. [CrossRef]

90. Terzidis, M.A.; Prisecaru, A.; Molphy, Z.; Barron, N.; Randazzo, A.; Dumont, E.; Krokidis, M.G.; Kellett, A.; Chatgilialoglu, C. Radical-induced purine lesion formation is dependent on DNA helical topology. Free Radic. Res. 2016, 50, S91-S101. [CrossRef] 
91. Fleming, A.M.; Burrows, C.J. Interplay of Guanine Oxidation and G-Quadruplex Folding in Gene Promoters. J. Am. Chem. Soc. 2020, 142, 1115-1136. [CrossRef]

92. Chatgilialoglu, C.; Ferreri, C.; Krokidis, M.G.; Masi, A.; Terzidis, M.A. On the relevance of hydroxyl radical to purine DNA damage. Free Radic. Res. 2021. [CrossRef]

93. Chatgilialoglu, C.; Ferreri, C.; Geacintov, N.E.; Krokidis, M.G.; Liu, Y.; Masi, A.; Shafirovich, V.; Terzidis, M.A.; Tsegay, P.S. 5',8-Cyclopurine lesions in DNA damage: Chemical, analytical, biological and diagnostic significance. Cells 2019, 8, 513. [CrossRef]

94. Yu, Y.; Cui, Y.; Niedernhofer, L.J.; Wang, Y. Occurrence, biological consequences, and human health relevance of oxidative stress-induced DNA damage. Chem. Res. Toxicol. 2016, 29, 2008-2039. [CrossRef]

95. Jaruga, P.; Kirkali, G.; Dizdaroglu, M. Measurement of formamidopyrimidines in DNA. Free Radic. Biol. Med. 2008, 45, 1601-1609. [CrossRef]

96. Dizdaroglu, M. Oxidatively induced DNA damage and its repair in cancer. Mutat. Res. Rev. Mutat. Res. 2015, 763, 212-245. [CrossRef]

97. Cadet, J.; Davies, K.J.A.; Medeiros, M.H.G.; Di Mascio, P.; Wagner, J.R. Formation and repair of oxidatively generated damage in cellular DNA. Free Radic. Biol. Med. 2017, 107, 13-34. [CrossRef]

98. Cui, L.; Ye, W.; Prestwich, E.G.; Wishnok, J.S.; Taghizadeh, K.; Dedon, P.C.; Tannenbaum, S.R. Comparative analysis of four oxidized guanine lesions from reactions of DNA with peroxynitrite, single oxygen, and $\gamma$-radiation. Chem. Res. Toxicol. 2013, 26, 195-202. [CrossRef]

99. Fleming, A.M.; Burrows, C.J. Formation and processing of DNA damage substrates for the hNEIL enzymes. Free Radic. Biol. Med. 2017, 107, 35-52. [CrossRef]

100. Whitaker, A.M.; Schaich, M.A.; Smith, M.R.; Flynn, T.S.; Freudenthal, B.D. Base excision repair of oxidative DNA damage: From mechanism to disease. Front. Biosci. 2017, 22, 1493-1522.

101. Shafirovich, V.; Geacintov, N.E. Removal of oxidatively generated DNA damage by overlapping repair pathways. Free Radic. Biol. Med. 2017, 107, 53-61. [CrossRef]

102. Kumar, N.; Raja, S.; Van Houten, B. The involvement of nucleotide excision repair proteins in the removal of oxidative DNA damage. Nucleic Acid Res. 2020, 48, 11227-11243. [CrossRef]

103. Buxton, G.V.; Greenstock, C.L.; Helman, W.P.; Ross, A.B. Critical review of rate constants for reactions of hydrated electrons, hydrogen atoms and hydroxyl radicals $\left.\left({ }^{\bullet} \mathrm{OH}\right) /{ }^{\bullet} \mathrm{O}^{-}\right)$in aqueous solution. J. Phys. Chem. Ref. Data 1988, 17, 513-886. [CrossRef]

104. Bobrowski, K. Radiation induced radical reactions. In Encyclopedia of Radicals in Chemistry, Biology and Materials; Chatgilialoglu, C., Studer, A., Eds.; John Wiley: Hoboken, NJ, USA, 2012; Volume 1, pp. 395-432. 